\title{
Development of integrated earthquake simulation system for Istanbul
}

\author{
Abdurrahman Sahin ${ }^{1 *}$, Rafet Sisman ${ }^{1}$, Aysegul Askan² and Muneo Hori ${ }^{3}$
}

\begin{abstract}
Recent advances in computing have brought a new and challenging way to tackle the earthquake hazard and disaster problems: integration of the seismic actions in the form of numerical models. For this purpose, integrated earthquake simulation (IES) has been developed in Japan, and now a new version is being developed in Turkey which targets Istanbul. This version of IES is being built in MATLAB and includes site response analysis and structural analysis of existing buildings with data obtained via GIS databases. In this study, we present an initial application in Zeytinburnu district of Istanbul where the results are expressed in the form of spatial distributions of ground motion and building responses. At the end of the analysis, it is seen that most of the buildings make small displacements and the displacement values are directly proportional to the total height of the structures. Since the obtained ground motion distribution and peak values are not very high, structural damage has not been observed under the current simulation. The effect of bedrock depth and soil parameters on strong ground motion distribution has been observed. The most effective ground motion locations in the selected area have been determined, and the critical buildings that have maximum displacement during the earthquake motion are detected. Currently, the IES on MATLAB does not include the source to bedrock wave propagation mechanism and the resulting ground motions at each grid point. In future studies, alternative models for this purpose along with input model parameters for Istanbul will be applied. Once the source-to-structure integrated model is complete, past earthquakes as well as potential scenario events in Istanbul will be modeled in the final form of IES on MATLAB. Results will be valuable for a variety of purposes ranging from disaster mitigation to emergency management. In future part of this study, site vibration tests will also be made for buildings that do not comply with seismic design codes and constitute the largest portion of the seismic risk. New models will be developed for these buildings and adopted into the IES system.
\end{abstract}

Keywords: Integrated earthquake simulation, Full-scale models, Earthquake disaster simulation, Earthquake hazard simulation, Virtual city, SoVeLAB, CitySeis

\section{Background}

It is essential for earthquake engineering to continuously develop a tool of making higher reliable estimation of earthquake hazard and disaster which could take place in a growing urban area. At this moment, we have to rely on empirical relations that are deduced from statistical analysis of data of past events. The reliability of such empirical relations is limited, because they are not able to take into consideration the changes made in the target urban

\footnotetext{
*Correspondence: abdsahin@yildiz.edu.tr

1 Department of Civil Engineering, Yıldız Technical University, Istanbul, Turkey

Full list of author information is available at the end of the article
}

area, such as use of better design codes and construction materials, social and economical growth in various aspects, or industrial requests for undisturbed business activities. However, it is also true to find an alternative of the present tool, since, ironically, the development of the urban area accelerates the increase in quality and quantity of information that is needed for reliable estimation of earthquake hazard and disaster.

In view of fast progress of computer hardware and software, there is a possibility of developing a new tool of making reliable estimation of earthquake hazard and risk, which is based on numerical simulation of all the processes of the hazard and disaster, see Fig. 1. Such a tool could make predictions for potential disasters for 


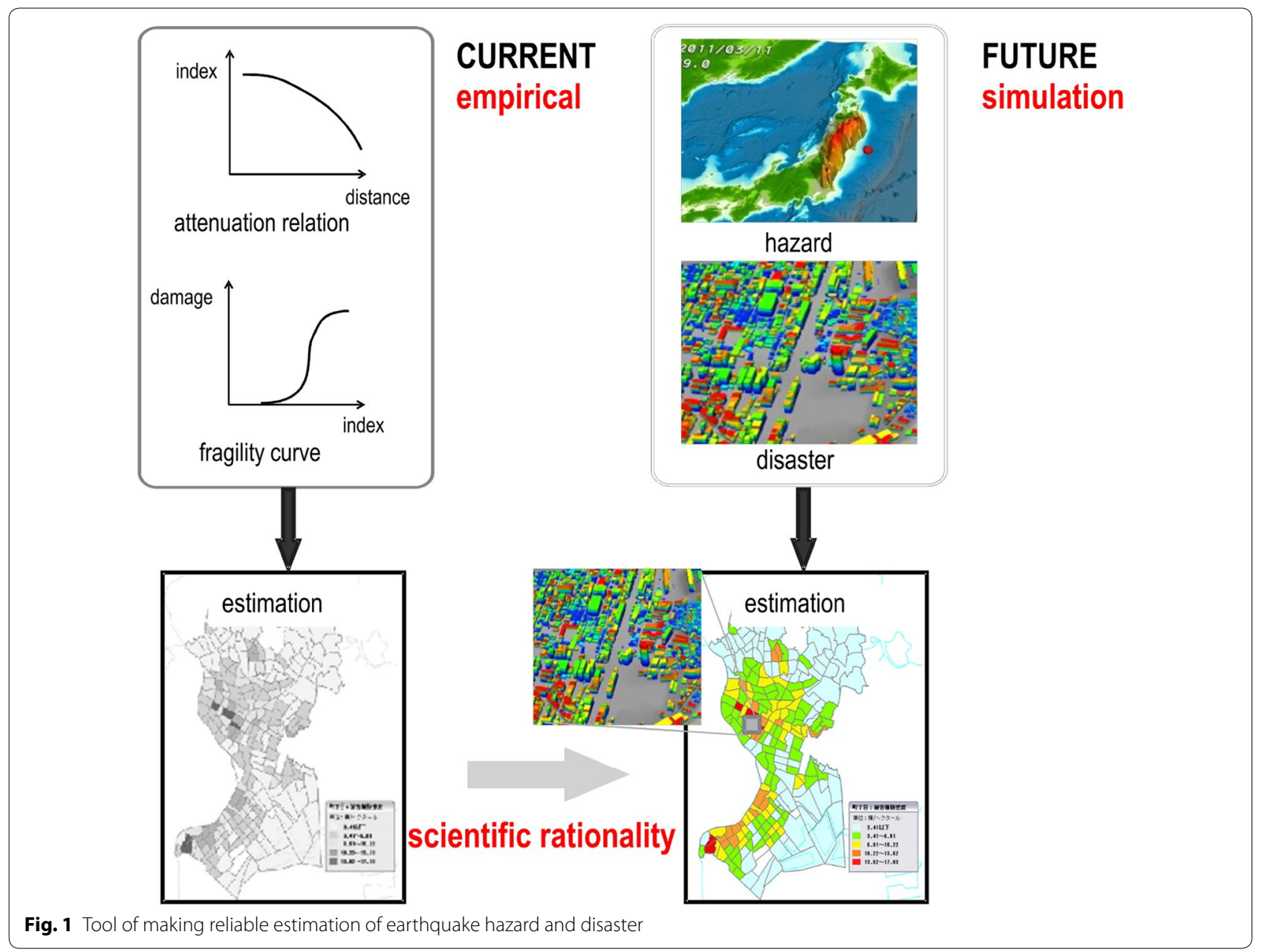

new facilities and functionalities of urban area and could handle the increase of available information. This tool has two sets of elements: the first set for various numerical analysis methods which simulates each process of earthquake hazard or disaster and the other set for constructing a suitable model for each numerical analysis method.

Integrated earthquake simulation (IES) is a candidate of the numerical simulation-based tool, see Hori (2007) and Hori and Ichimura (2008). IES has been developed in Japan, and a new version is being developed in Turkey which targets Istanbul. While the basic concept of IES of the Japanese version is shared, IES of the Turkish version must have its own features. This is mainly because the numerical analysis methods and the urban area information available are different in these two countries. It is not possible to implement IES of the Japanese version to Turkey as it is. Therefore, IES of the Turkey version is developed as a new version.

There are many advanced rapid earthquake loss estimation systems in the literature. The review of current quick disaster estimation systems may be found in (Erdik et al.
2011). These systems interpolate seismic intensity indices recorded at observation stations, and the structural damage is estimated. Local soil conditions are expressed in terms of amplification factors. In this study, physicsbased numerical simulation system that analyzes the seismic responses of soil and structures is being developed.

In this paper, we present the current state of developing IES of Turkey version, which is built on the MATLAB environment (2015) rather than UNIX of LINUX environment of IES of the Japanese version. MATLAB is an advanced simulation and programming package. It has advanced graphical and mathematical capabilities and is widely used in system development for structural and earthquake engineering applications (Sahin 2011, 2012, 2015a, b).

The content of this paper is as follows: Firstly, the key features of new IES are explained. They involve numerical simulation of seismic wave amplification processes that take place in shallow ground structures and numerical simulation of structural seismic response of each residential building. Then, the current stage of IES on 
MATLAB is summarized and corresponding future work is outlined.

\section{IES system developed on MATLAB}

As explained previously, advanced numerical simulations may be used for predicting earthquake hazards and disasters. Large-scale numerical simulations may be carried out due to the developed computer science and technology. In this process, all phases of a possible earthquake should be simulated. Numerical simulation should give researchers further information about estimation of variability in earthquake disasters due to different earthquake scenarios. The amount and complexity of the data to be used for earthquake hazard and disaster simulations of large areas require the use of user-friendly and advanced graphical interface systems. With the advances in computer technologies, the computer-aided design (CAD) has been developed. MATLAB is one of the representatives of high-performance language for the CAD. It can be used for modeling, simulating, and analyzing dynamic systems. It supports linear and nonlinear systems, modeled in continuous and discrete time. Simulation is an interactive process, so the parameters may be altered, while the simulation is running and the system response may be immediately monitored.

A new user-friendly and graphical user interface-based system development for earthquake hazard and disaster simulation of urban areas has been started (Sahin 2014). The system is planned to include all phases of IES system. The final aim of the system is to simulate earthquake strong ground motion from source to site, structural damages, and human behavior during the earthquake. The long-term objective is simulation of emergency evacuation and short- and long-term social and economic recovery. It is possible to automatically construct a computer model for a city of some hundred kilometers scale using the latest geographical information system (GIS). It can be said that new IES system provides vital information to see the possible effects of future earthquake hazards and disasters.

High-performance computing enhancement was made, so that urban area models of higher fidelity were analyzed in shorter times and ensemble simulation which accounted for uncertainties in modeling the earthquake hazard and disaster processes could be made. The uncertainties in modeling the earthquake hazard and disaster processes are material or structural properties. It is not possible to remove these uncertainties, but we can account for it by providing a probabilistic distribution of seismic response carrying out ensemble computing. It should be noted that material property uncertainty is not significant for a structure if input ground motion is small. But the uncertainty provides wider range of responses if input ground motion is large and the structure has a chance of being damaged. Full-scale vibration tests will be carried out to eliminate structural uncertainties, and structural models will be developed.

It should be indicated that high-performance computing can be directly applied to the IES system developed on MATLAB by using Parallel Computing Toolbox. Multicore processors, GPUs, and computer clusters can be used to solve computationally and data-intensive problems. The applications developed in MATLAB can be parallelized without CUDA or MPI programming. High-level constructs parallel for loops, special array types, and parallelized numerical algorithms can be used for parallelization (Parallel Computing Toolbox ${ }^{\mathrm{TM}}$ User's Guide 2015).

In IES system, physical modeling is used and more detailed modeling decreases the uncertainties. The soil models are directly developed from site observations, and seismic behavior of soil models can be observed. The uncertainties in soil models and hazard simulations have been eliminated significantly by integrating all soil test data such as borehole, ReMi, and PS Log. The integration algorithms are used for producing more accurate soil models. The mesh grid intervals could be shortened after considering all data sets with GIS format, and more reliable soil models could be generated.

In building models, it could be possible to predict detailed 3D FEM models from the estimated multidegree-of-freedom (MDOF) models. Detailed time history analysis of thousands of buildings could be possible owing to high-performance computing. As indicated before, more detailed models decrease the uncertainties in modeling.

\section{Automatic soil model generation and earthquake hazard simulation tool-SoVeLAB}

The ground motion prediction is the first step of earthquake damage assessment. This analysis generally consists of two processes. In the first process, the ground motion on seismic bedrock is calculated. In the second process, the soil effects are evaluated by considering seismic site amplification (site response analysis). The surface ground motion can be predicted by considering both processes. Wave propagation in seismic bedrock is evaluated in the first process, and wave propagation in soil surface is evaluated in the second process.

The seismic bedrock motion can be considered with three ways: (1) converting observed rock outcrop motion into bedrock motion, (2) directly applying a seismic record or random record as a bedrock motion, and (3) obtaining bedrock motion from the source by applying wave propagation techniques.

The surface ground layer model may be constructed by using a set of geotechnical data, which include boring, PS 
logging, or passive seismic methods such as microtremor and refraction microtremor (ReMi). An algorithm is used to automatically construct three-dimensional soil model. In the proposed algorithm, interpolation and extrapolation between neighboring ReMi and boreholes are performed.

The collected field data are scattered over the study area, and it is required to get them gridded with respect to generated mesh. This mesh generation is automatically done by developed system. Automatic interpolation is utilized, and soil profile can be obtained at any point on the produced mesh. The mesh generation process is summarized in Fig. 2.

Soil profiles at any point on mesh are generated by determining each layer's top and bottom elevation. Borehole data are utilized for determining the top and bottom elevations of the layers. Figure 3 shows the procedure used to combine soil profiles at borehole locations. In the developed system, the procedure is conducted in threedimensional domain. The upper and lower boundaries of the soil layers are combined. If any layer is not encountered in a borehole log, the following soil layer from the stratigraphy is assigned in place of it. These modifications mean that every formation exists in all borehole logs, but in some of them the nonexisting formations have zero thickness.

After that process layer thicknesses at any point in the study can be calculated by only interpolation. The same procedure is applied for generating the velocity model. The soil and velocity models are then integrated. The velocity information at any depth of ReMi test locations is obtained, and the same procedure is used to combine them.

To generate soil model of a selected urban area from borehole and refraction microtremor test data, a new MATLAB code, named as SoVeLAB (Soil Velocity Laboratory), was developed. The flow diagram given in Fig. 4 represents the algorithm of this program. Firstly, SoVeLAB reads the area data which includes the boundary coordinates of the region being studied. At this step, SoVeLAB generates a uniformly gridded mesh between the defined boundary coordinates. Secondly, SoVeLAB reads the borehole and refraction microtremor test data from the GIS database. Then, SoVeLAB visualizes the altitude map of the
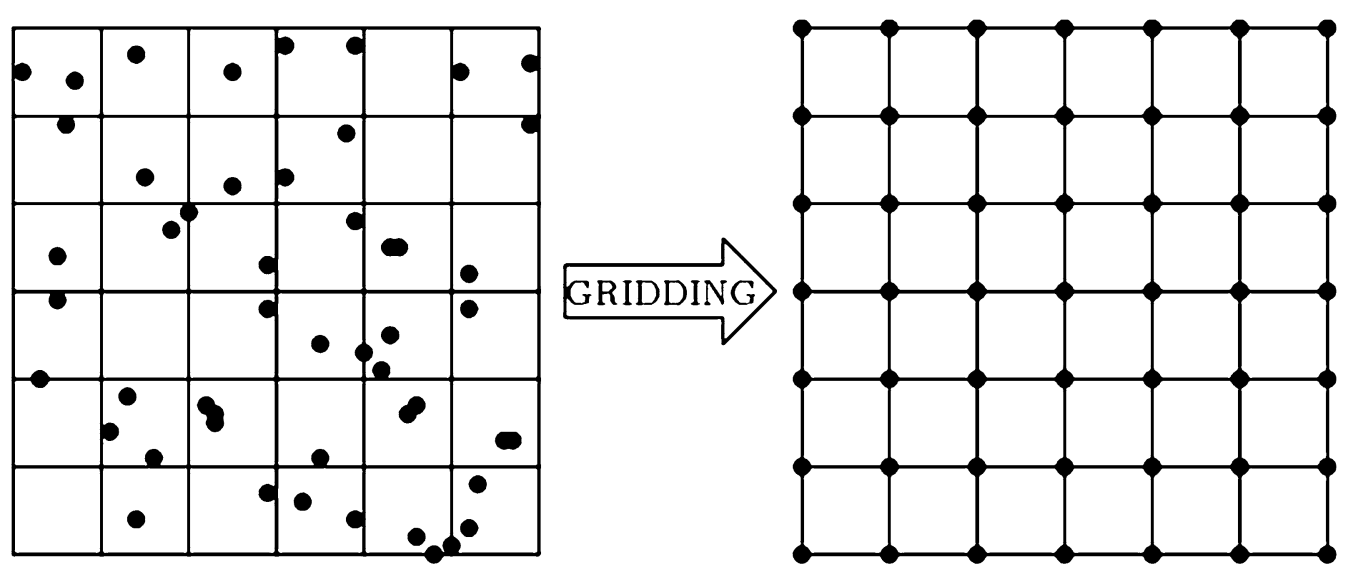

Fig. 2 Automatic interpolation and mesh generation process

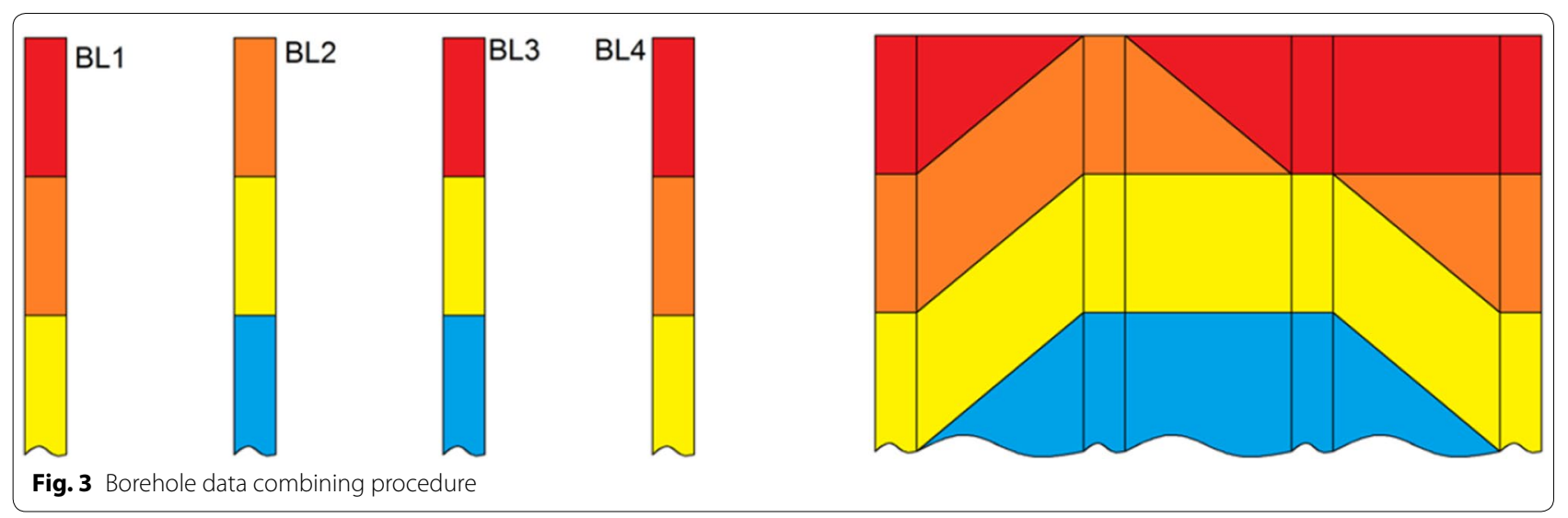




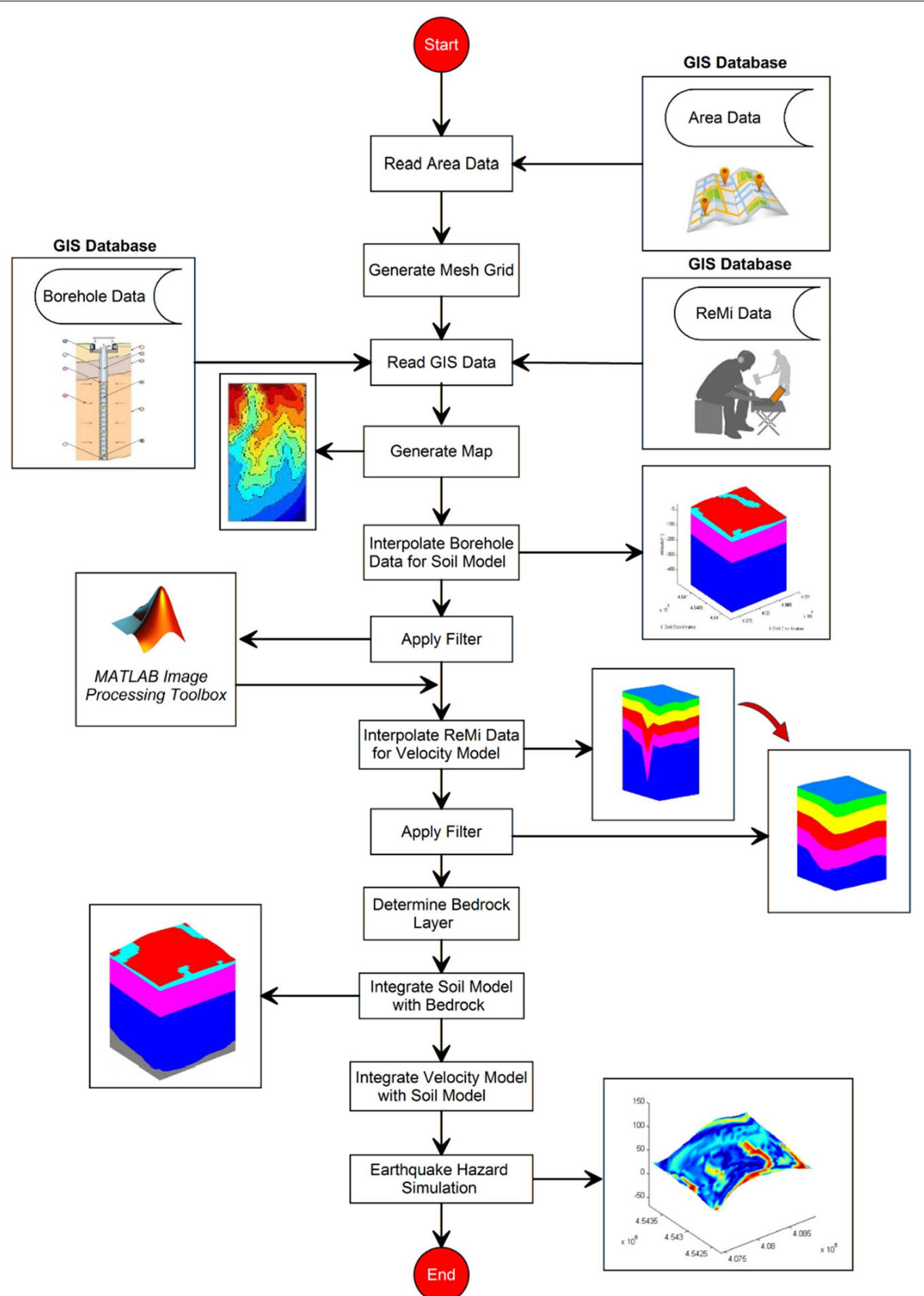

Fig. 4 Flowchart of the developed system for automatically soil model generation from GIS data

study region by utilizing the $x, y$ coordinates and altitude of site test location. Interpolating the borehole test data, SoVeLAB produces the primer soil model including layer boundaries, while interpolating the layer depths, SoVeLAB uses a filter mask to filter out unrealistic results. MATLAB Image Processing Toolbox filtering functions are used for 
median filtering. Median filtering seems more effective than convolution technique if it is aimed to simultaneously reduce noise and preserve edges. After generation of primer soil model, SoVeLAB interpolates refraction microtremor test data and generates the velocity model. Firstly, the study area is divided into small cell and the data sets are combined by linear interpolation. The shear wave velocities at each $1 \mathrm{~m}$ depth for each observation stations are determined up to the maximum depth reached. Then, the velocity values over the study area for each $1 \mathrm{~m}$ depth are interpolated. This procedure successfully generates the three-dimensional digital velocity model. To ensure that unrealistic data are thrown out, velocity model is also filtered. The system is filtered according to median value of neighboring matrix elements. According to the Vs value representing the engineering bedrock, SoVeLAB determines the bedrock depth and integrates bedrock layer with primer soil model and generates main soil model. Finally, SoVeLAB combines velocity model and soil model to use in site response analyses.

It should be noted that two-dimensional median filtering is used for eliminating unrealistic test data. Median filtering is a nonlinear filtering operation and widely used in image processing. It can be seen that a median filter is very effective in automatic soil model generation with great variety and great number of data.

\section{Automatic city model generation and earthquake disaster simulation tool-CitySeis}

City simulation consists of earthquake hazard simulation and earthquake disaster simulation. In this section, the development of earthquake disaster simulation system is explained. A new virtual city simulator called CitySeis has been developed for earthquake disaster simulation of urban areas (Sahin 2014). The MDOF models are automatically generated from the GIS data. The global corner coordinates of the buildings, building type, number of stories, and other useful data can be read from GIS database, and the mass, stiffness, and rigidity matrices are automatically generated. The detailed information for this procedure can be found in Hori (2007).

It should be noted that the GIS data include building type, number of stories, and global coordinates of the buildings. The structural model is generated by using these data. The system does not need material properties, and the stiffness and mass matrices are directly obtained with iteration process.

Any earthquake data can be loaded into the system, and earthquake analysis of the virtual city is carried out. The virtual city is automatically generated from the GIS data, and the building inventory is analyzed under earthquake motion. The behavior of each building in the virtual city may be observed and evaluated.
The advanced graphical and simulation capabilities of MATLAB are used. The computer model of surface ground layers and the computer model of residential building assembly are automatically constructed by making use of data stored in available GIS. In the developed system, an algorithm for constructing a linear MDOF system for a residential building with the aid of available GIS data is used. The input data for this algorithm are the global coordinates of the building, story height, and building type.

\section{Application of new IES system for Istanbul}

It should be emphasized that many comprehensive studies were carried out to satisfy the needs of loss assessment processes in Istanbul after the destructive Marmara earthquakes affected urban areas of Marmara Region in 1999. Japan International Cooperation Agency (JICA) prepared a "Study on Disaster Mitigation/prevention in Istanbul Including Seismic Microzonation" (Pacific Consultants International/OYO Corporation 2002). After this study, Earthquake Master Plan for Istanbul (EMPI) has been prepared by Istanbul Metropolitan Municipality in corporation with four leading Turkish universities. Due to the need of rapid earthquake loss estimation systems for large-scale areas, some software systems have been developed suitable to Istanbul database. Earthquake Loss Estimation Routine (ELER) has been developed within NERIES project JRA3 workpackage for rapid estimation of earthquake shaking and losses throughout the EuroMediterranean region (Erdik et al. 2010; Hancilar et al. 2010). HAZTURK (MAEviz-Istanbul) software has been developed based on the MAEviz of Mid-America Earthquake Center to visualize the earthquake risk and its possible damage to structures and people (Karaman et al. 2008a). The applications of these tools mentioned here have been conducted for some parts of Istanbul (Karaman et al. 2008b; Sesetyan et al. 2011). Additionally, many comprehensive studies have been carried out in order to assess the seismic risks in Istanbul (Atakan et al. 2002; Erdik et al. 2003; Bal et al. 2008; Ansal et al. 2009). However, none of the studies carried out for Istanbul were able to provide an integrated system that generates physical models of urban areas including soil and structural systems. The proposed system automatically generates virtual city and simulates earthquake hazard and disaster.

This section presents examples of applying the developed system to Istanbul for prediction of earthquake hazards and disasters. The virtual city is a computer model of a real town, which is constructed in Zeytinburnu district of Istanbul. The size of the target area is $1000 \mathrm{~m} \times 1000 \mathrm{~m}$ as shown in Fig. 5 .

The virtual city is constructed by using the data stored in several GIS's, which are available for Zeytinburnu 
district. The location of available borehole and ReMi measurements in Zeytinburnu district is presented in Fig. 6. These data are available in Istanbul Metropolitan Municipality (IMM) servers, and the models are developed by using the database in the IMM servers.

The initial three-dimensional (3D) soil model is automatically generated by interpolating the borehole data for the developed grid points. The boundaries of each layer are determined, and the initial parameters are assigned accordingly. The $3 \mathrm{D}$ velocity model of the selected area is also automatically generated by interpolating and extrapolating the observed ReMi data. The generated velocity model is filtered according to median value of neighboring matrix elements by using nonlinear median filtering.

The velocity distribution at the center of the model is shown in Fig. 7: The $X-Z$ section at $Y=4,543,550 \mathrm{~m}$ and the $Y-Z$ section at $X=408,250 \mathrm{~m}$ of the developed model are presented in this figure. It should be noted that "Z" represents the altitude of the soil model.

The developed initial soil model and velocity model are combined, and the final soil model is obtained as given in Fig. 8. The bedrock layer is determined from the velocity distribution. In this study the velocity of engineering bedrock is assumed as $760 \mathrm{~m} / \mathrm{s}$. The bedrock surface layer is presented in Fig. 9.
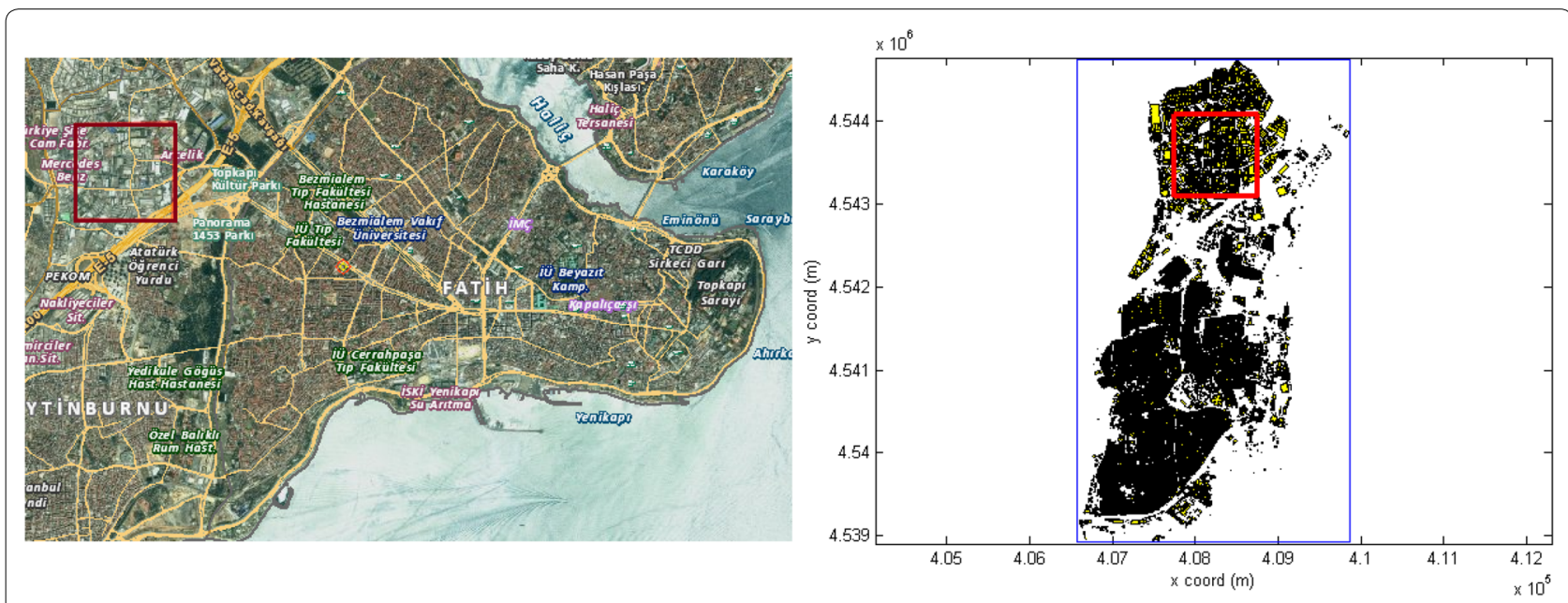

Fig. 5 A target area of a virtual city in İstanbul

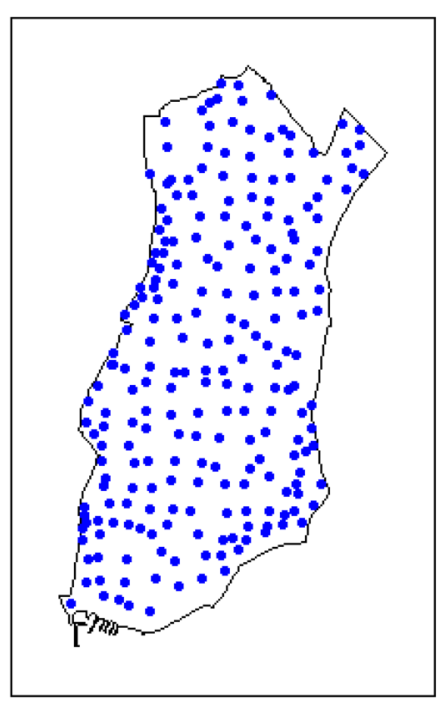

(a)

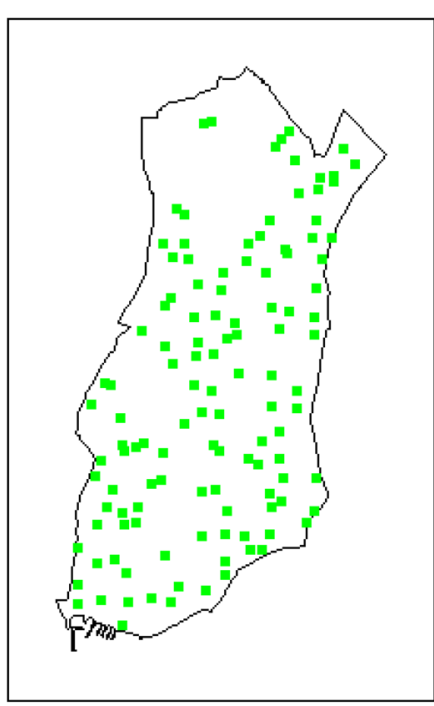

(b)

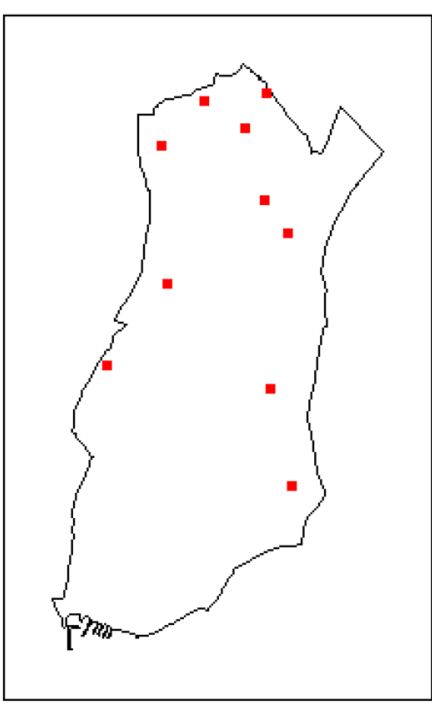

(c)

Fig. 6 Measurement locations in GIS database. a Borehole locations, b ReMi locations, c PS Log locations 

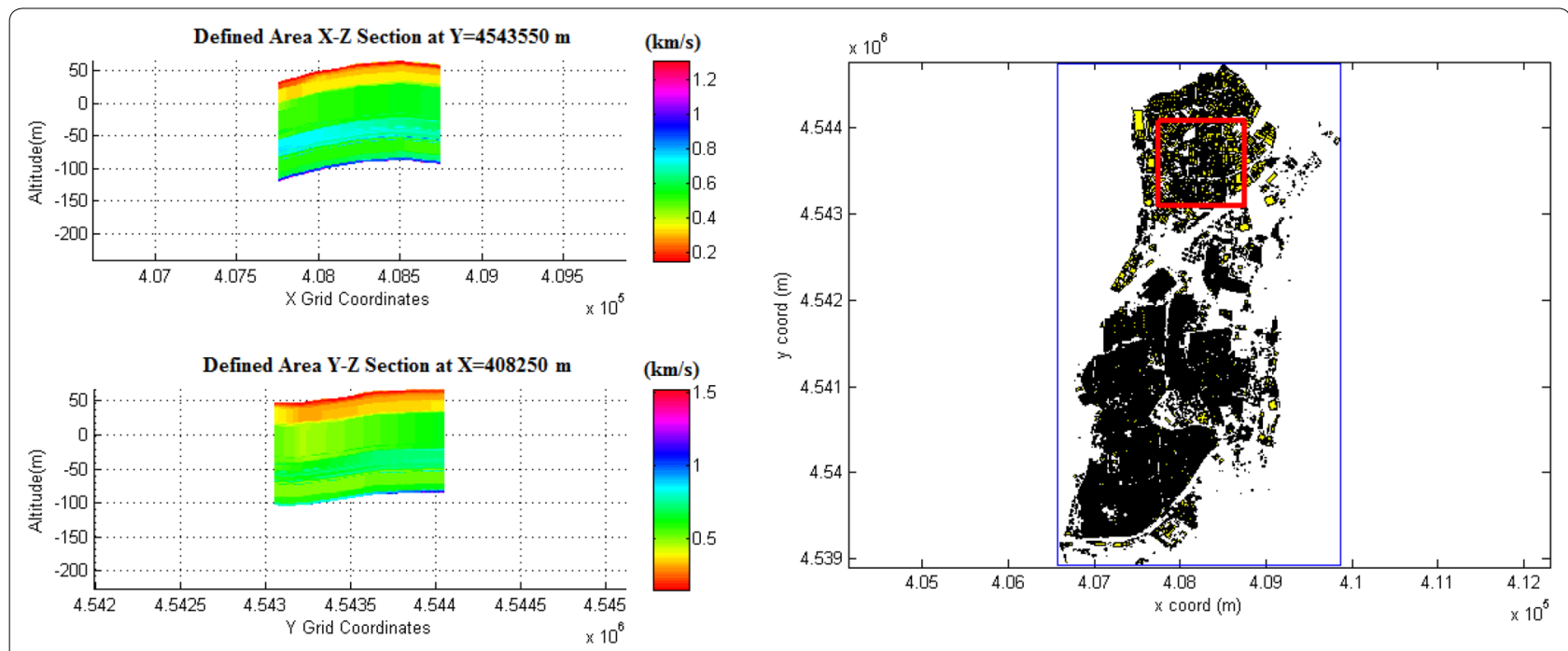

Fig. 7 Velocity distribution at the center of the model

In the next step, the virtual city is automatically generated. In the virtual city, there are 417 residential buildings where a MDOF system is constructed for each building. Data for the structure type, floor number, land usage, and the location of residential buildings are extracted from GIS database. Data collected from GIS database are automatically loaded into the system, and MDOF system is constructed as shown in Fig. 10.

\section{Input ground motion}

Strong ground motion which hits the virtual city is simulated by using one-dimensional site response analysis. The developed soil model is divided into same sized mesh grids, and the strong ground motion at each grid point is calculated. Time series ground motion data recorded at Zeytinburnu station in 1999 Kocaeli Earthquake that struck northwestern Turkey is used as input for site response analysis. The geodetic position of the

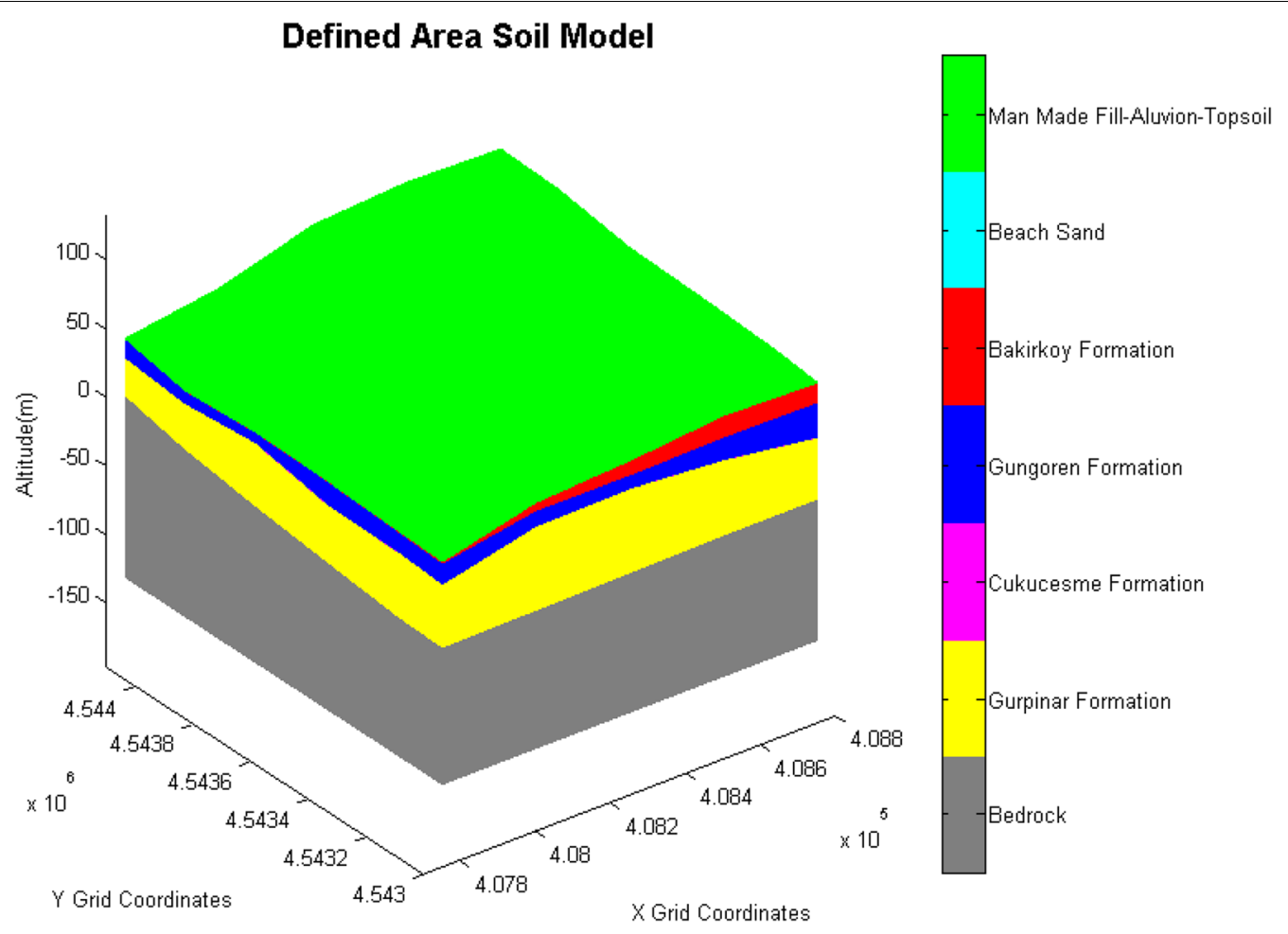

Fig. 8 Final computer model of the soil-structure 


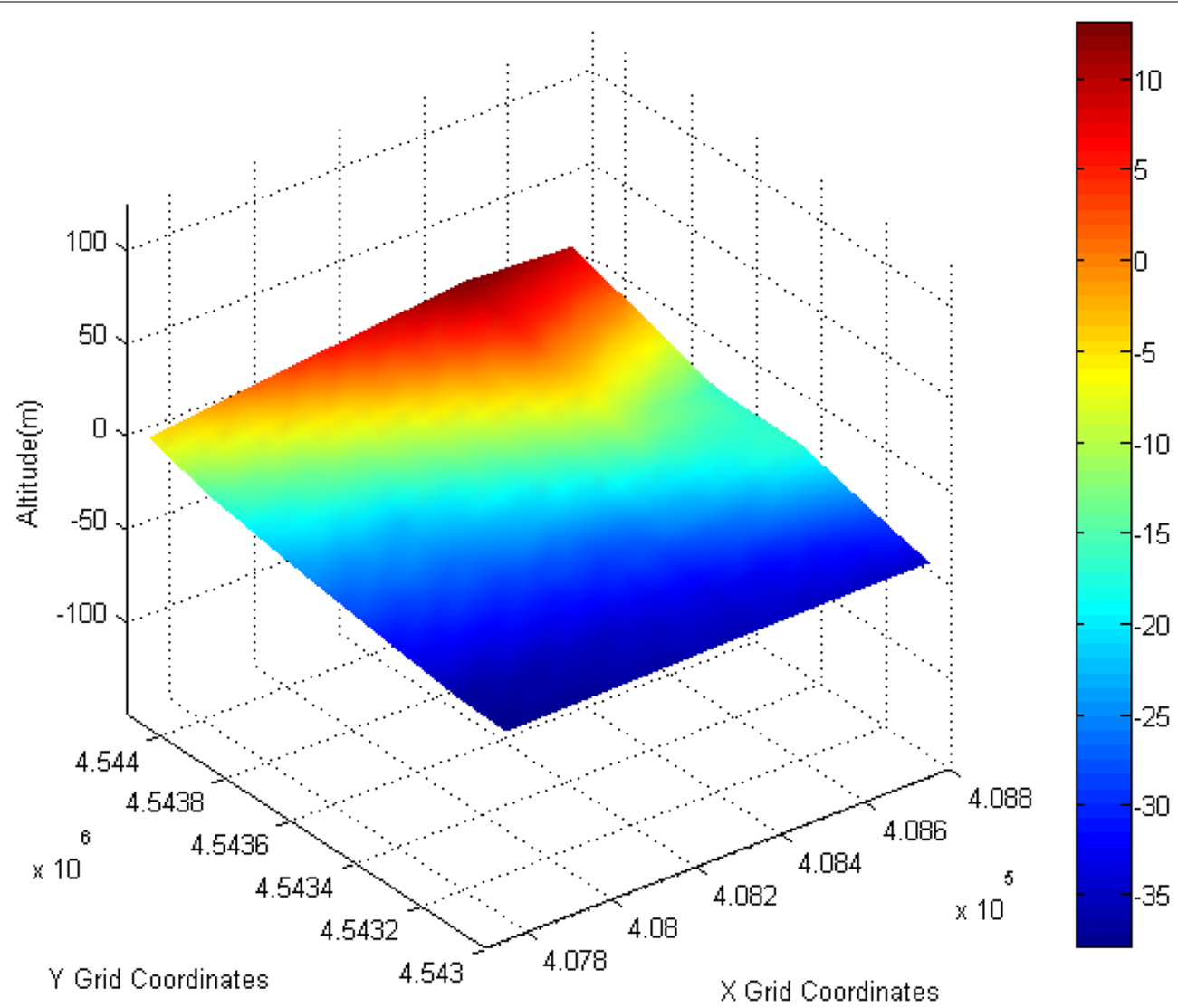

Fig. 9 Bedrock surface model defined at layer with $760 \mathrm{~m} / \mathrm{s}$ velocity

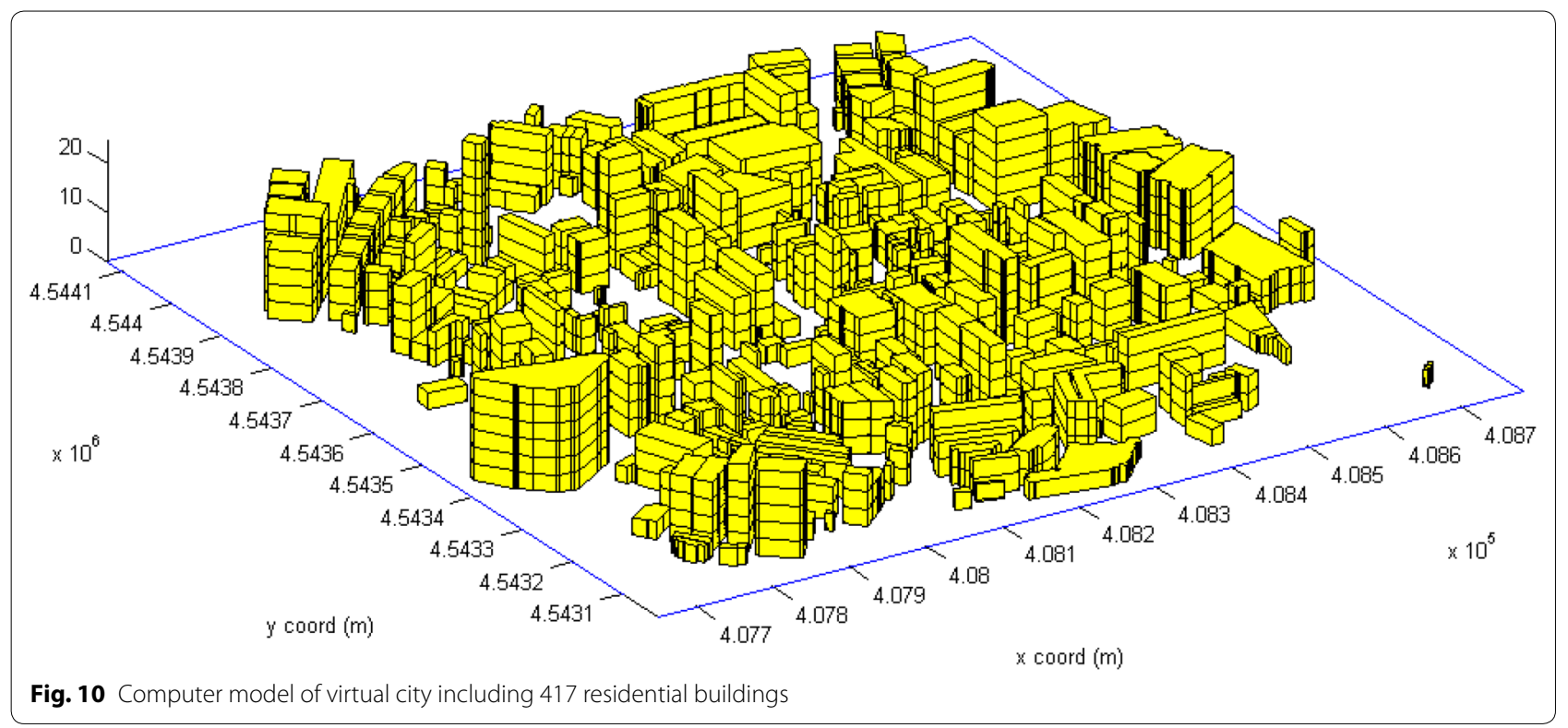


observation station is $28.9080^{\circ}$ longitude and $40.7270^{\circ}$ latitude as shown in Fig. 11. These seismic records are downloaded from Pacific Earthquake Engineering Research Center-PEER ground motion database (http://ngawest2.berkeley.edu/). The ellipsoidal coordinates converted into the Cartesian coordinates are introduced to developed system for conversion. The location of the observation station in Zeytinburnu district is also presented in the altitude map as shown in Fig. 11.

The soil profile of the observation station is automatically generated as shown in Fig. 12, and the measured records are converted into bedrock motion. The eastwest and the north-south components of the observed record and produced bedrock motions are given in Figs. 13 and 14, respectively. The obtained bedrock motion is transferred to the selected area, and 1D site amplification is calculated for all grid points generated in the virtual city.

As an example of the synthesized seismic motion at the surface, the distribution of the maximum displacements, velocities, and accelerations for the east-west and north-south directions is given in Figs. 15, 16, 17. The maximum displacement in the north-south direction is $8.79 \mathrm{~cm}$, and it is obtained at $t=52.54 \mathrm{~s}$. As shown in this figure, the strong ground motion is far from being uniform, and some concentration of large ground motion is observed.

\section{Seismic structure response}

Linear time history analysis is carried out for $417 \mathrm{MDOF}$ models of the residential buildings which are located in the virtual city. The simulated strong ground motion (SGM) at the site of each building is used as an input wave. Note that the MDOF models are isolated and no interactions among nearby buildings are considered as

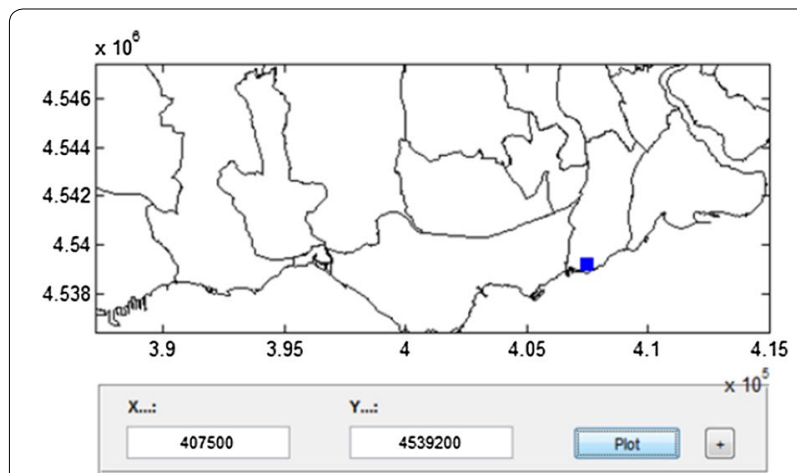

\begin{tabular}{|lc|}
\hline M.F. & 6.083252 \\
\hline Al. & 0 \\
\hline T.S. & 0 \\
\hline B.S. & 0 \\
\hline Ba.F. & 10.96705 \\
\hline Gn.F. & 16.63363 \\
\hline C.F. & 35.54901 \\
\hline Gr.F. & 165.0431 \\
\hline Bedrock \\
\hline
\end{tabular}

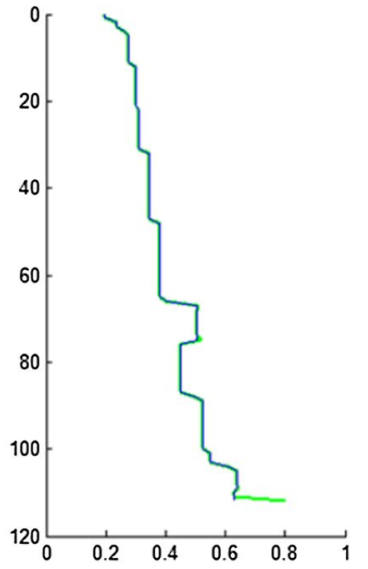

Fig. 12 Soil profile at observation station

well as no soil-structure interaction. In Figs. 18, 19, 20, and 21, earthquake hazards and disasters in $\mathrm{E}-\mathrm{W}$ and $\mathrm{N}-\mathrm{S}$ directions, which are predicted for the virtual town, are presented as a snapshot of the perspective of the virtual city. In these figures, strong ground motion distribution in terms of peak ground displacement (PGD) and structure response of all residential buildings is presented

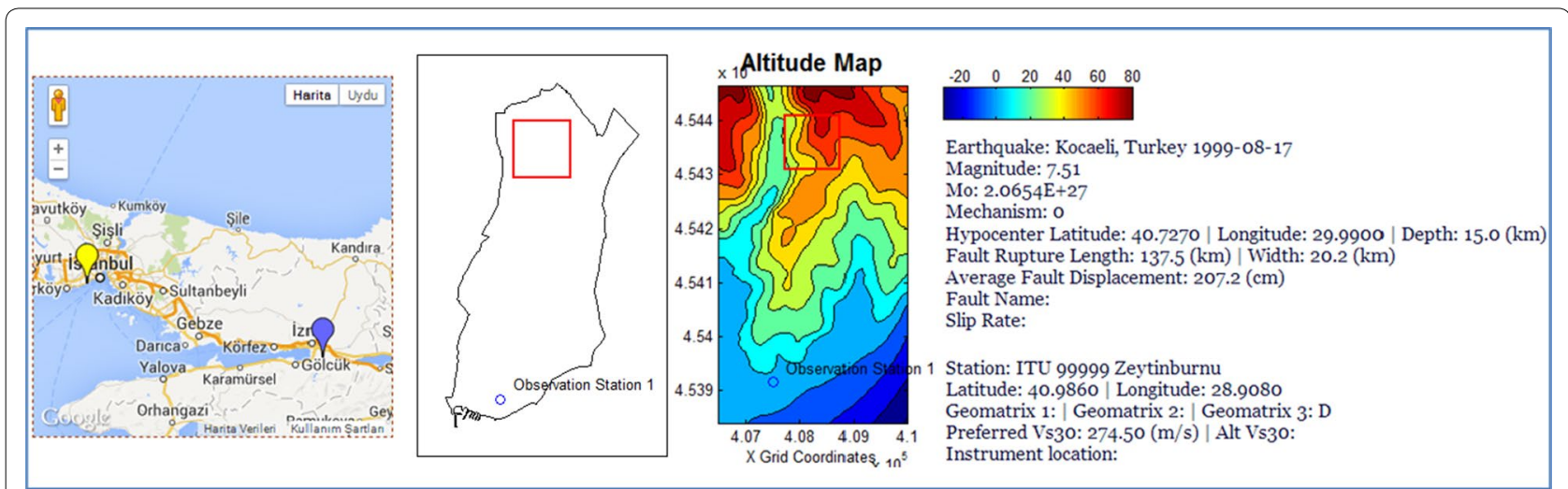

Fig. 11 The details of the used seismic data processed by Pacific Engineering (http://ngawest2.berkeley.edu/) 


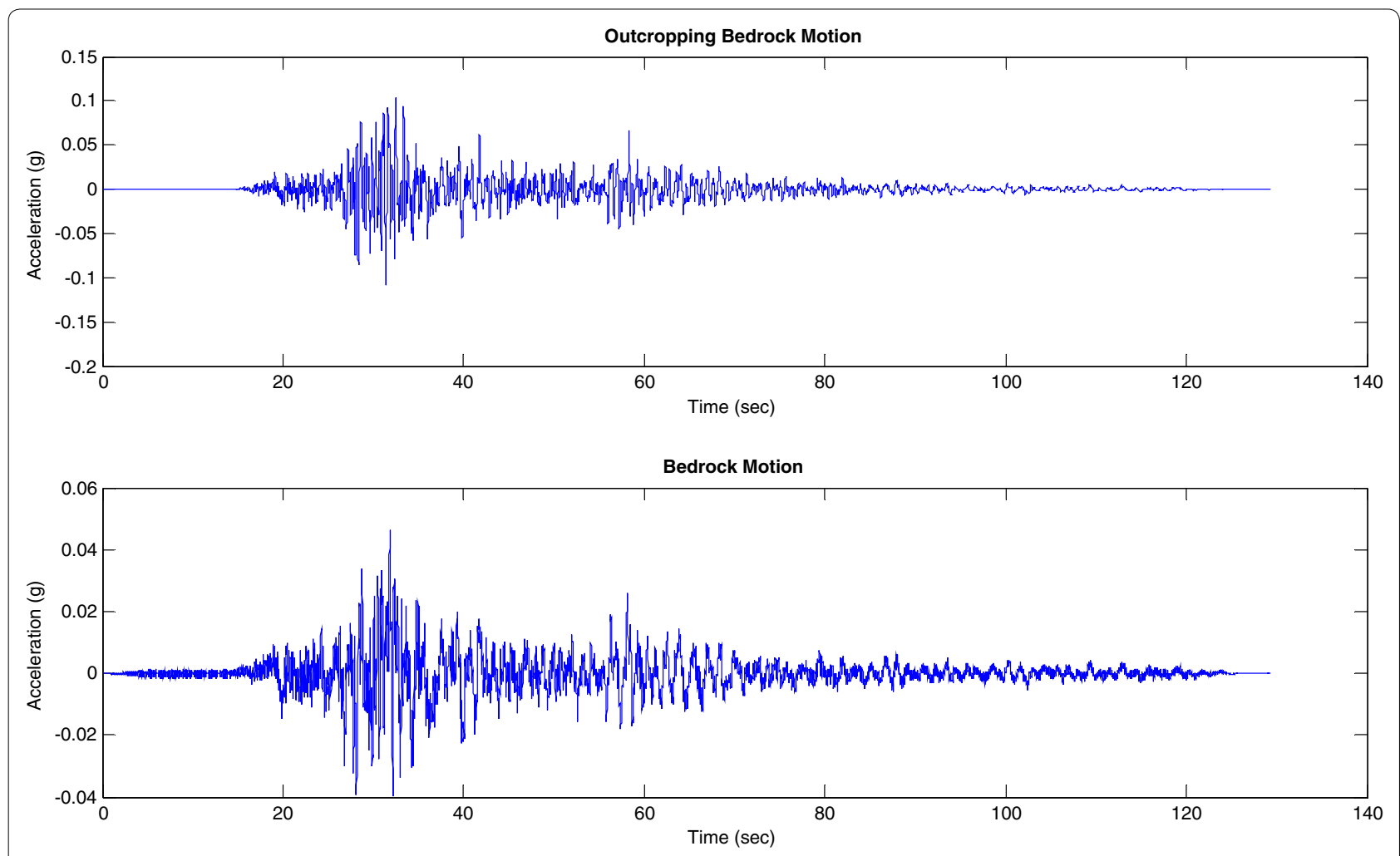

Fig. 13 East-west component of the observed outcrop earthquake record (ZYT090) and obtained bedrock motion

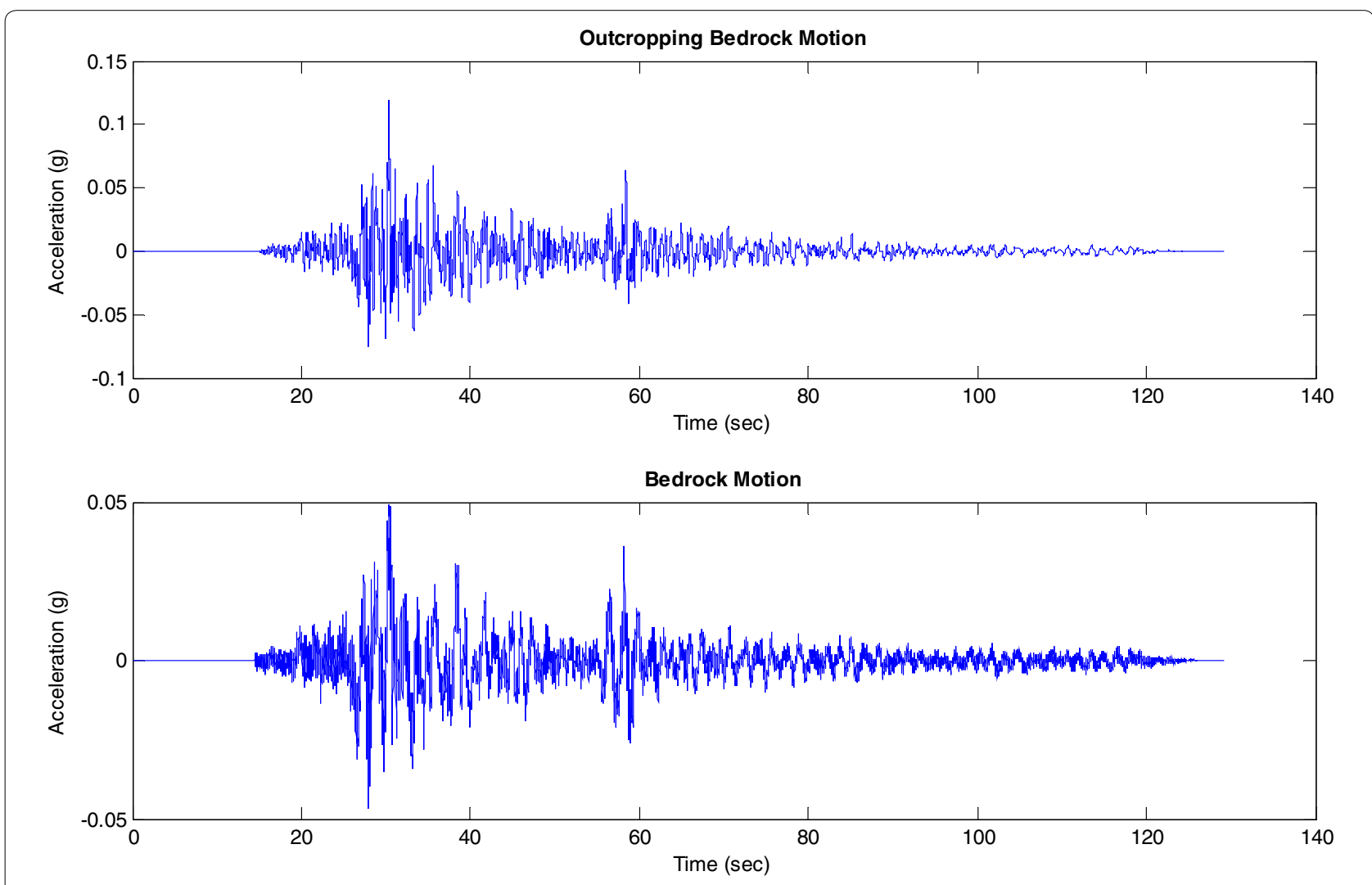

Fig. 14 North-south component of the observed earthquake record (ZYTO00) and obtained bedrock motion 


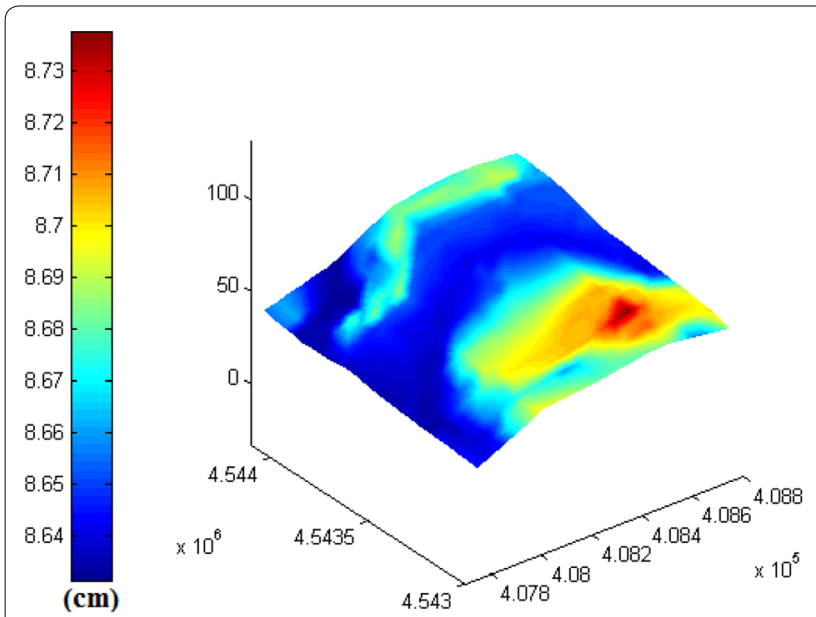

(a)

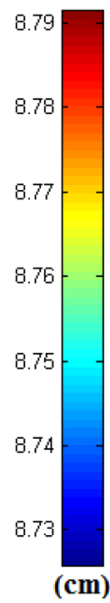

(cm)

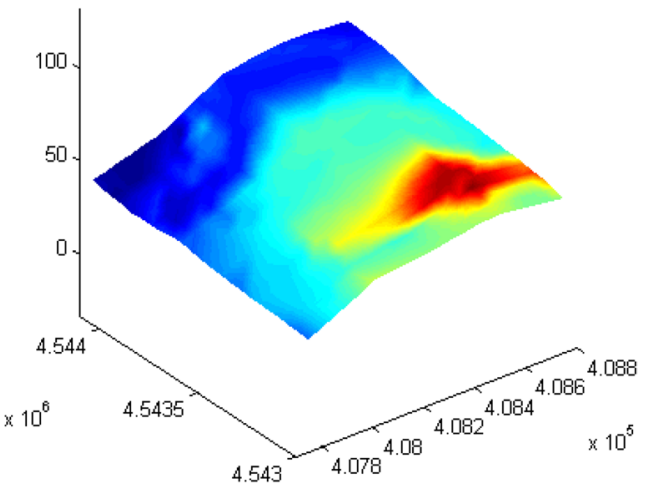

(b)

Fig. 15 The snapshot of the displacement distributions with maximum local values; $\mathrm{E}-\mathrm{W}$ and $\mathrm{N}-\mathrm{S}$ components ( $\mathrm{cm}$ ). $\mathbf{a} t=72.49 \mathrm{~s}, \mathbf{b} t=52.54 \mathrm{~s}$

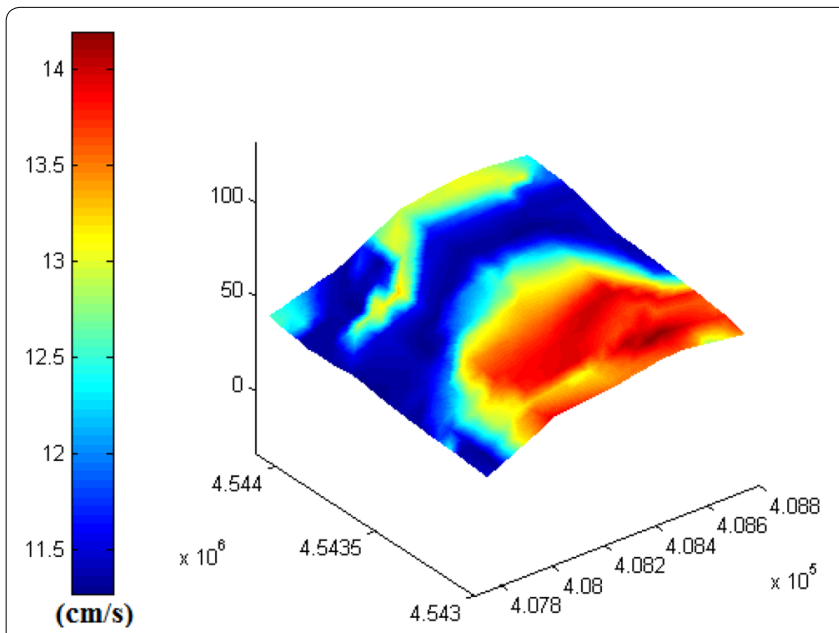

(a)
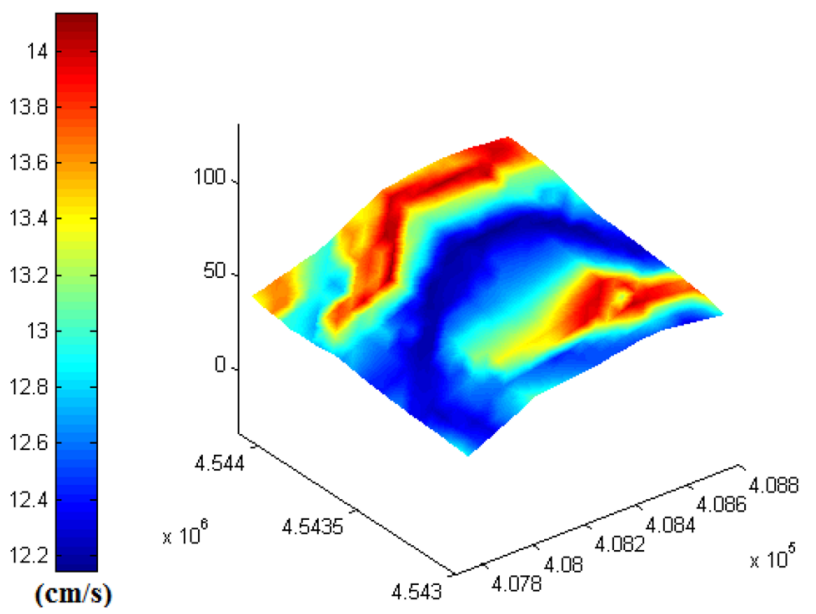

(b)

Fig. 16 The snapshot of the velocity distributions with maximum local values; $\mathrm{E}-\mathrm{W}$ and $\mathrm{N}-\mathrm{S}$ components $(\mathrm{cm} / \mathrm{s})$. $\mathbf{a} t=65.52 \mathrm{~s}, \mathbf{b} t=65.21 \mathrm{~s}$

for each $10 \mathrm{~s}$. These images are the output of the visualization tool that is implemented in the recently developed IES system.

The maximum displacement of each MDOF model in $\mathrm{E}-\mathrm{W}$ direction, $\mathrm{N}-\mathrm{S}$ direction, and combined direction is presented in Figs. 22, 23, 24. The related soil motions in $\mathrm{E}-\mathrm{W}$ direction and $\mathrm{N}-\mathrm{S}$ direction at the same times are also given in Figs. 22, 23. As expected, the maximum displacement becomes larger for buildings which are higher than others. It can be observed from the analysis results that the buildings have not caused seismic amplification very much. The maximum displacement values of the top of the buildings and the soil surface are very close to each other.

The virtual town is constructed for the selected part of Zeytinburnu district, with MDOF models for 417 buildings. Topographical effects may cause concentration of ground motion and induces larger response of the 


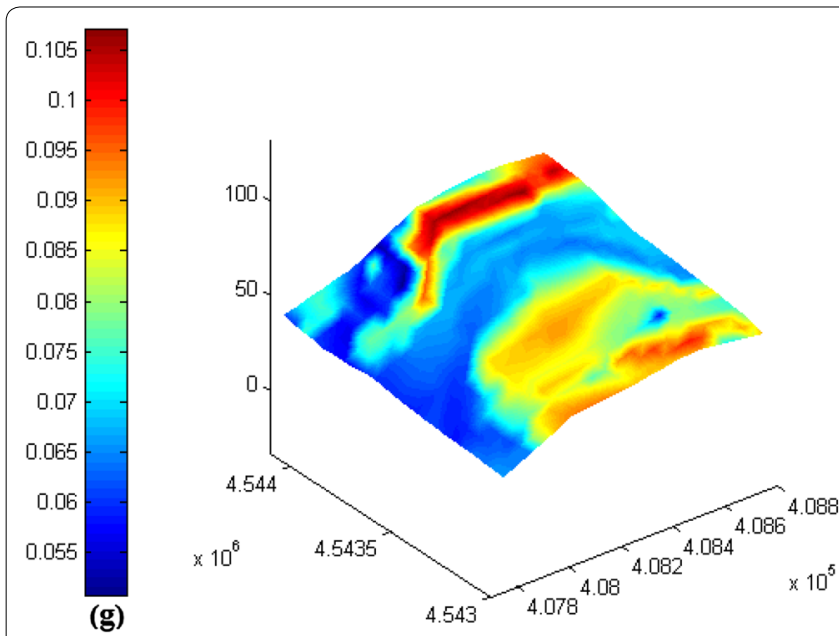

(a)

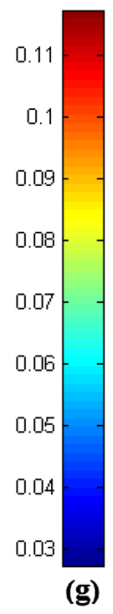

(g)

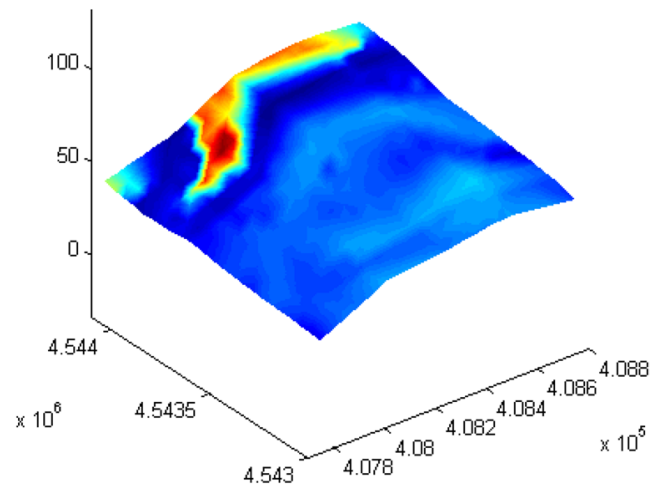

(b)

Fig. 17 The snapshot of the acceleration distributions with maximum local values; E-W and N-S components (g). a $t=61.6 \mathrm{~s}, \mathbf{b} t=35.605 \mathrm{~s}$

MDOF models. Further studies including two- or threedimensional soil model analysis are surely necessary to clarify structure damage induced by such topographical effects. It is the core functionality of new IES that makes it possible to evaluate possible damages in each residential building. For mode exclusive information about possible earthquake hazard and disaster which may happen in Istanbul, an urban area model needs to be extended to all Istanbul, by using available GIS. It is also necessary to employ a more sophisticated model for residential building if sufficient data are stored in GIS or reasonable guess of structure properties is allowed.

It should be emphasized that the initial version of the software module has been presented and now 1D site amplification analysis is ready. In the next stage of the project, we plan to develop 2D and 3D analysis modules. 3D soil models are generated for further studies which takes layer slope effects into account, since the studied area that has a smooth ground surface using 1D site amplification was very efficient and sufficient.

\section{Concluding remarks}

In this study, IES on MATLAB is introduced for Istanbul with ground motion and building response modules. An application is presented herein where the results are expressed in terms of spatial distribution of peak ground motion parameters as well as dynamic building responses. As of now, IES on MATLAB uses the same bedrock motion at all grid points and employs a deconvolved record measured in Istanbul during the 1999 Kocaeli earthquake as input to the site response analyses.

At the end of the analyses, it is seen that the displacement distribution of the virtual city is very limited although some tall buildings make very high displacements. Since the obtained ground motion distribution and peak values are not very high, no damage has been observed in the virtual city under the current simulation. The most active areas depending on the site response simulations have been determined, and the critical buildings that have maximum displacement during the earthquake motion are detected. The structural damage distribution in virtual city can be observed, and loss estimation can be made by using the produced soil and structural response data under earthquake records.

In current study, the structural models are automatically developed by assuming that all buildings comply with seismic design codes. For the case of Istanbul, buildings having severe irregularities (e.g., soft/weak story, discontinuous framing) and those that do not comply with seismic design codes, constitute the largest portion of the seismic risk. In future part of this study, site vibration tests will be made for hundreds of buildings and new models will be developed for Istanbul building inventory.

In its current situation, IES system on MATLAB does not yet include the wave propagation from the fault plane to each site of interest. At every site, however, 

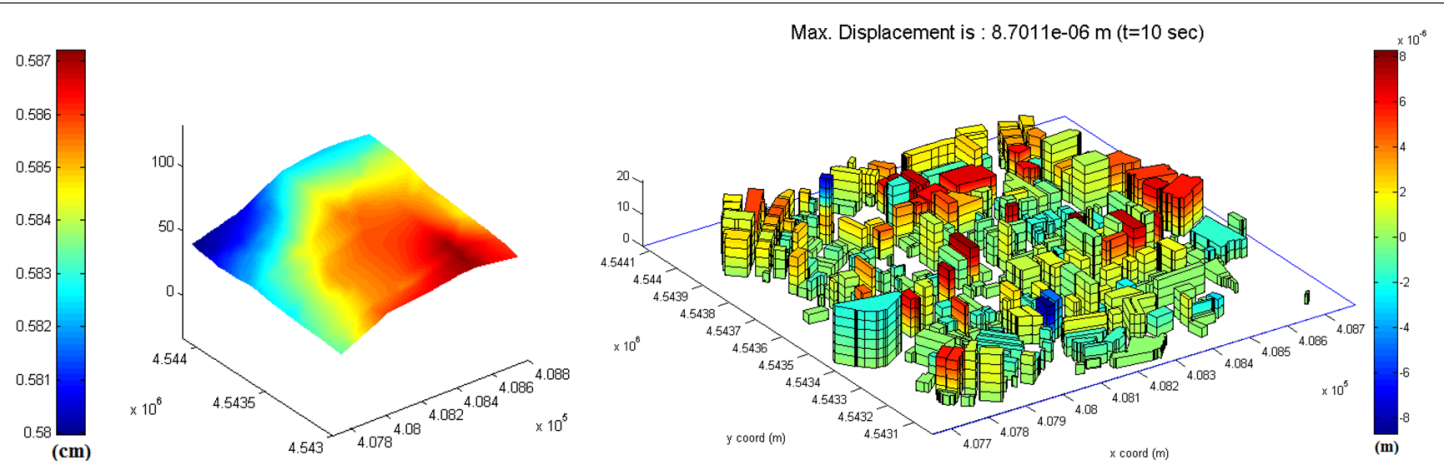

(a)
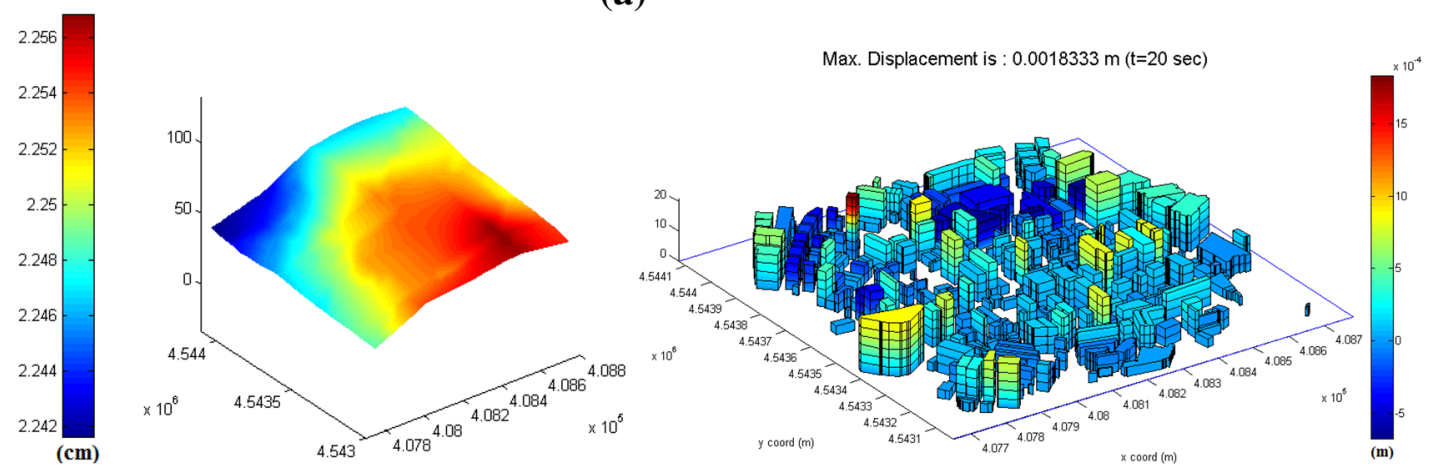

(b)
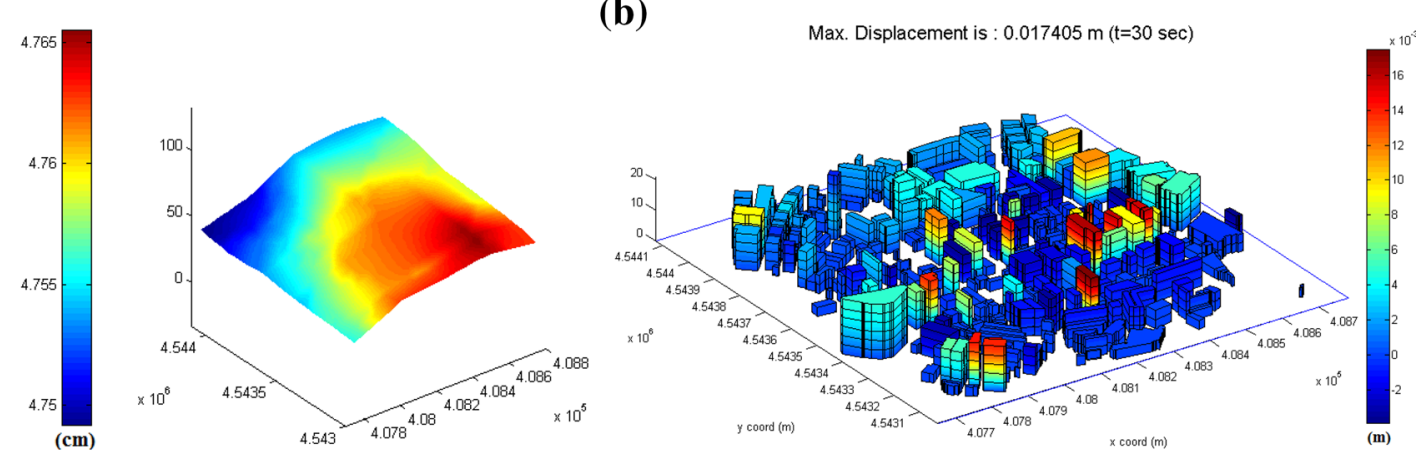

(c)
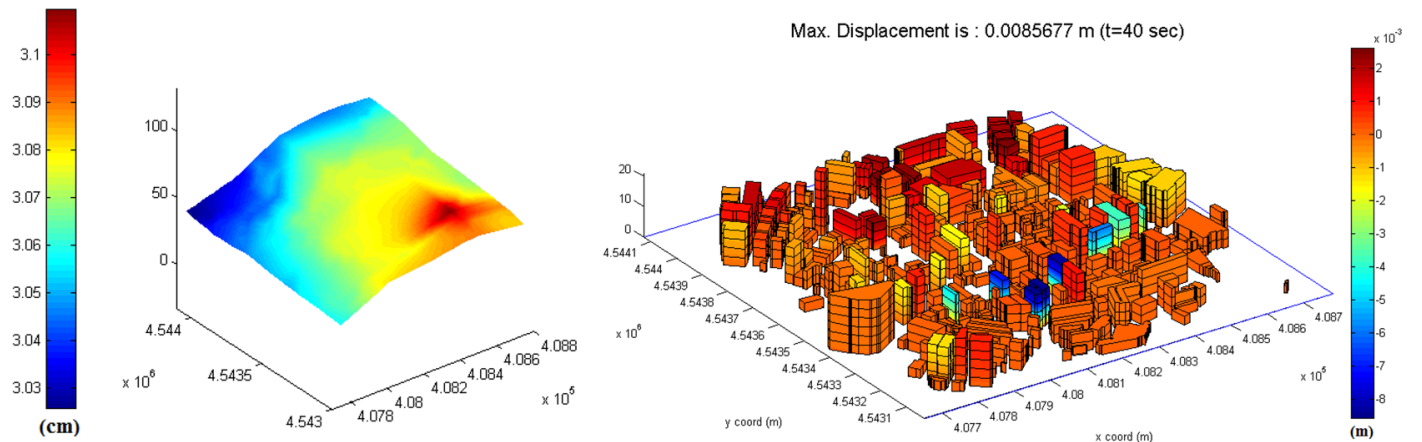

(d)

Fig. 18 Snapshots of the SGM distribution and the building set response in E-W direction. a $t=10 \mathrm{~s}, \mathbf{b} t=20 \mathrm{~s}, \mathbf{c} t=30 \mathrm{~s}, \mathbf{d} t=40 \mathrm{~s}$ 

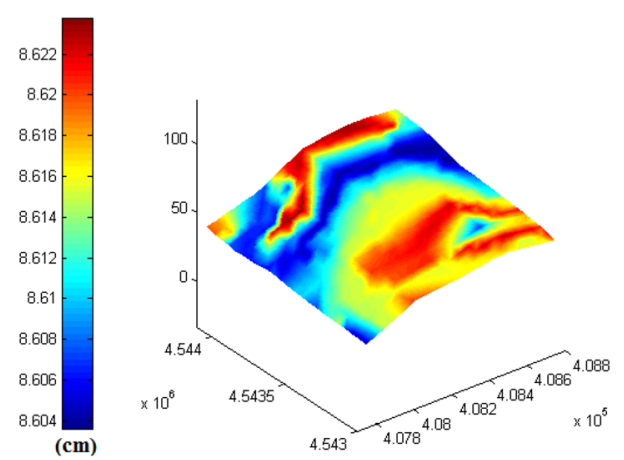

(a)
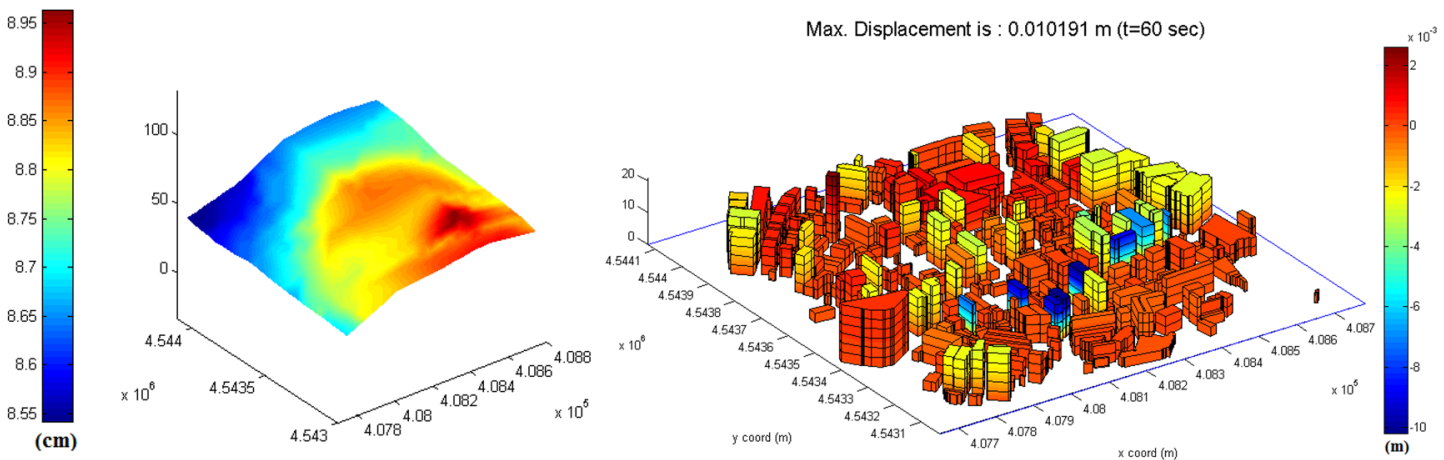

(b)
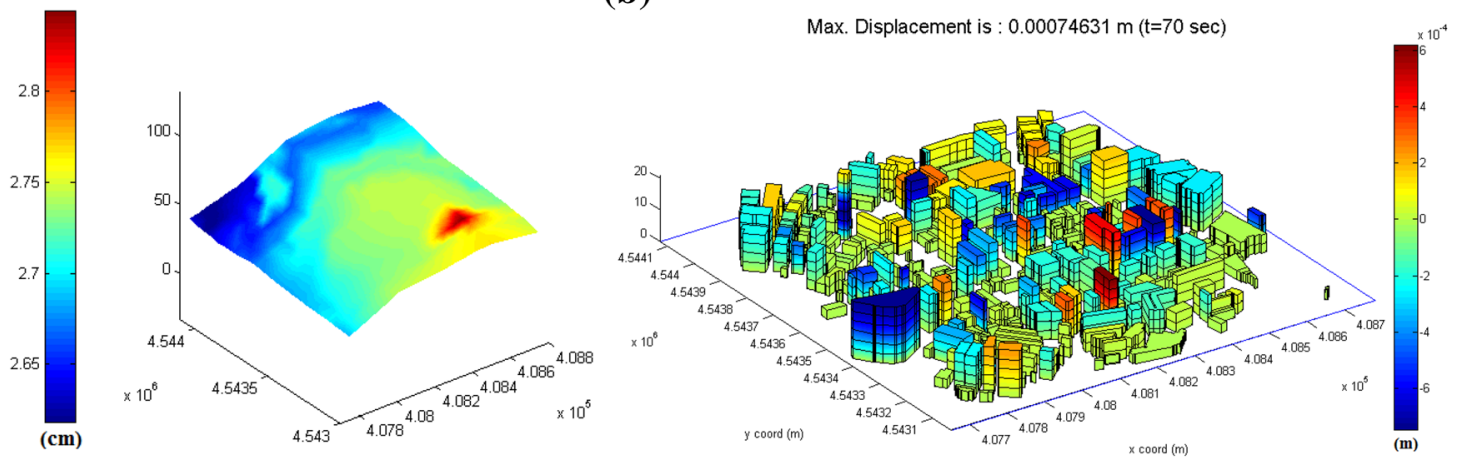

(c)
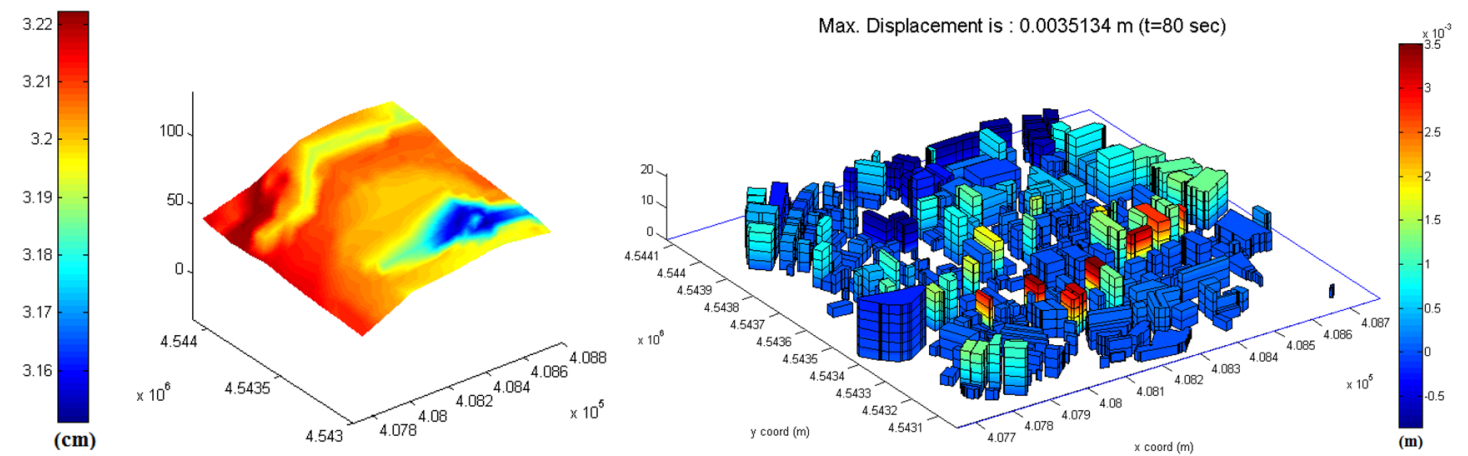

(d)

Fig. 19 Snapshots of the SGM distribution and the building set response in E-W direction. a $t=50 \mathrm{~s}, \mathbf{b} t=60 \mathrm{~s}, \mathbf{c} t=70 \mathrm{~s}, \mathbf{d} t=80 \mathrm{~s}$ 

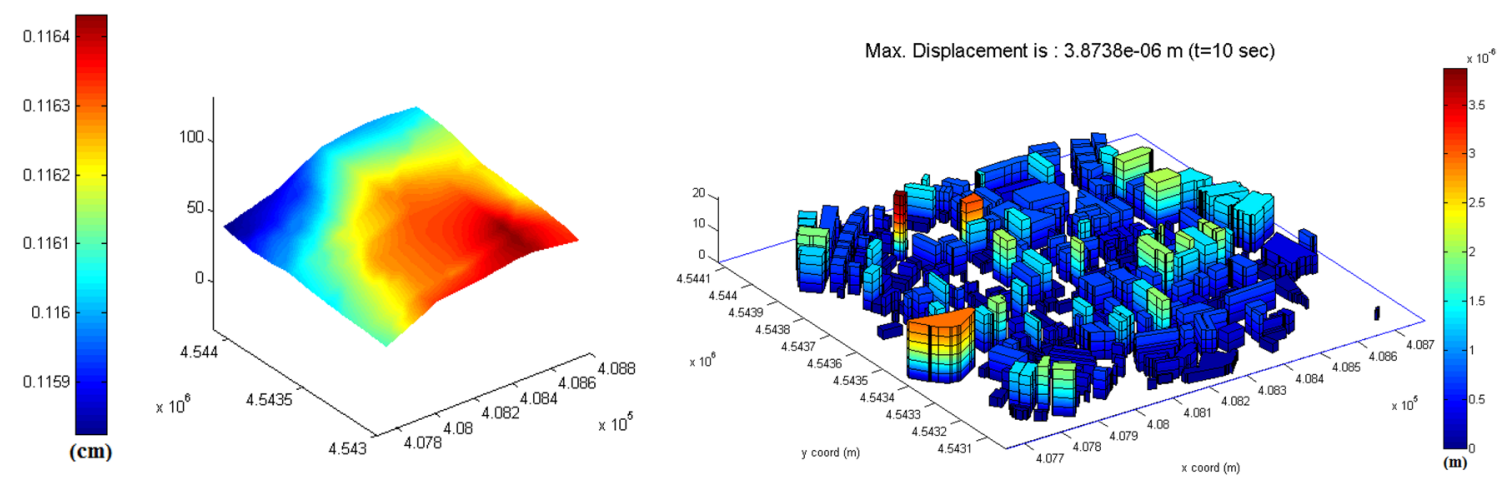

(a)
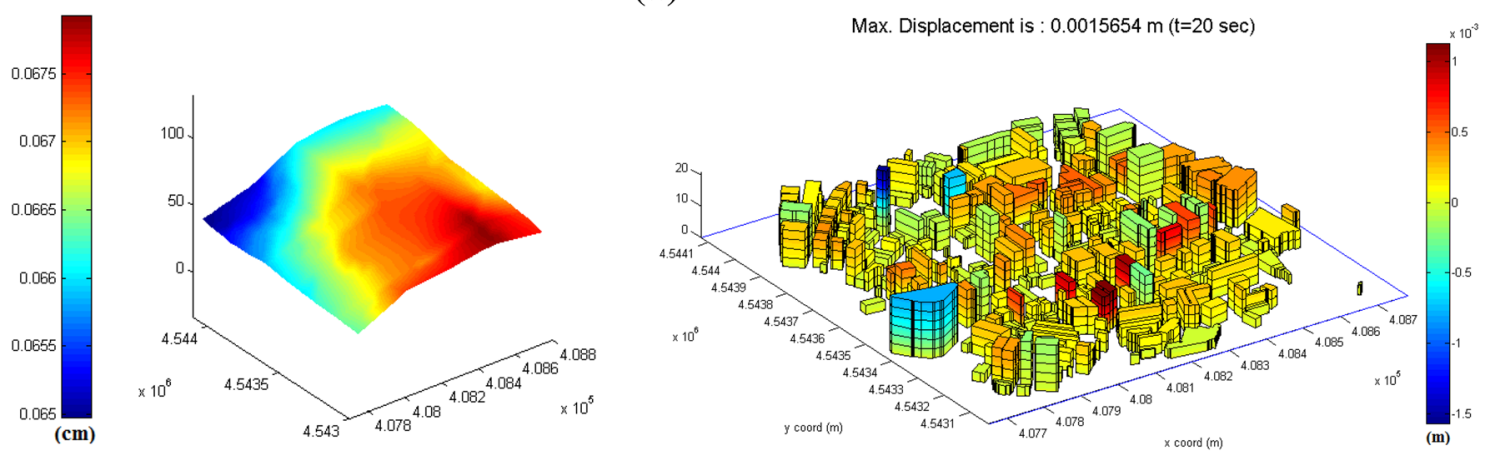

(b)
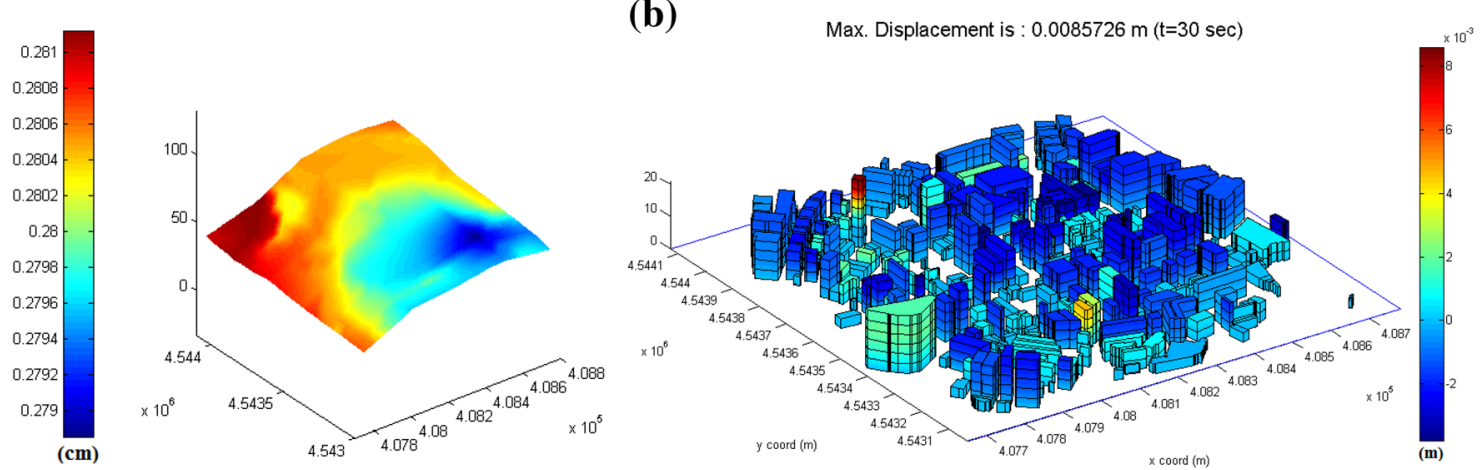

(c)
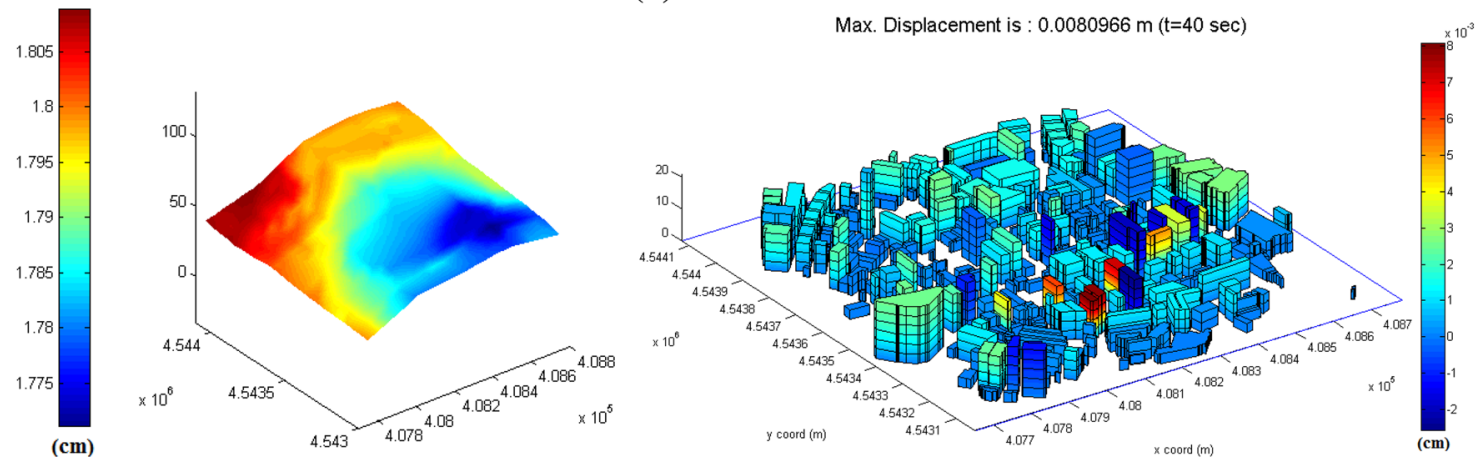

(d)

Fig. 20 Snapshots of the SGM distribution and the building set response in $\mathrm{N}-\mathrm{S}$ direction. $\mathbf{a} t=10 \mathrm{~s}, \mathbf{b} t=20 \mathrm{~s}, \mathbf{c} t=30 \mathrm{~s}, \mathbf{d} t=40 \mathrm{~s}$ 

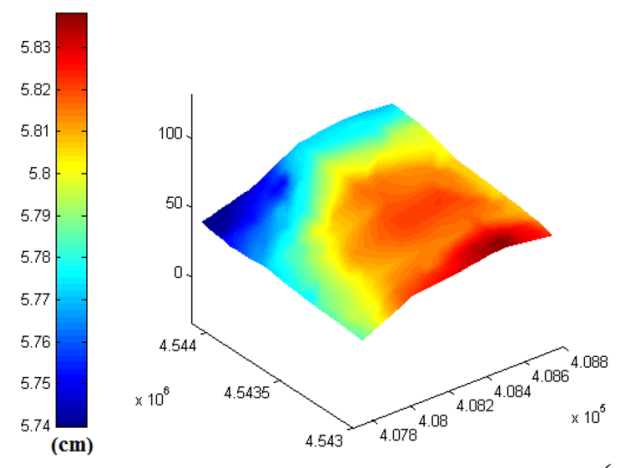

(a)

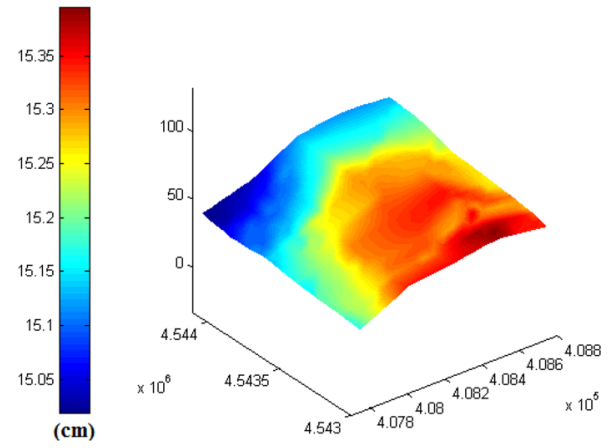

(b)
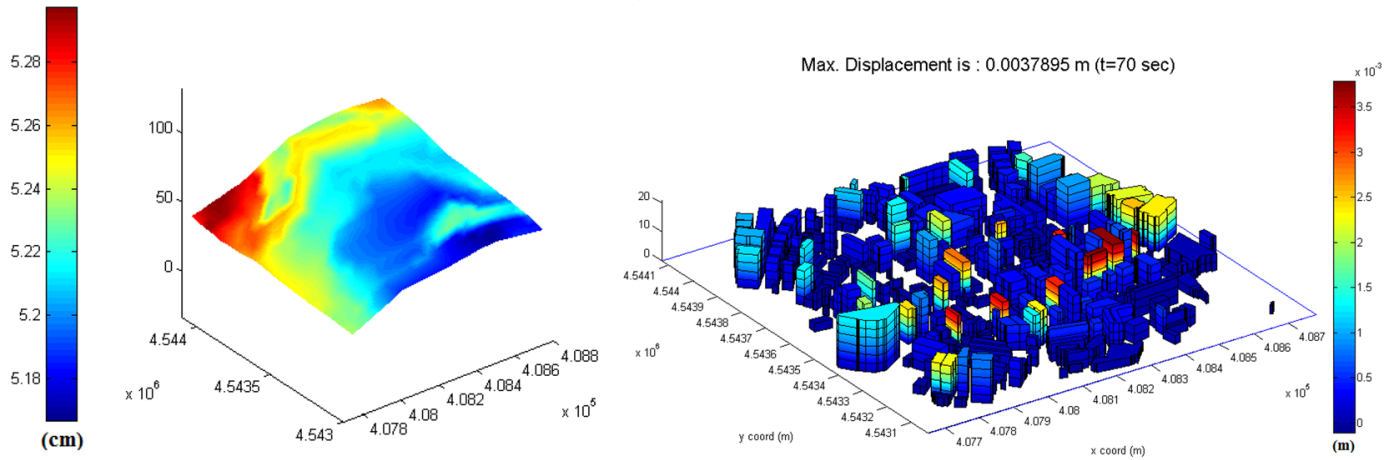

(c)
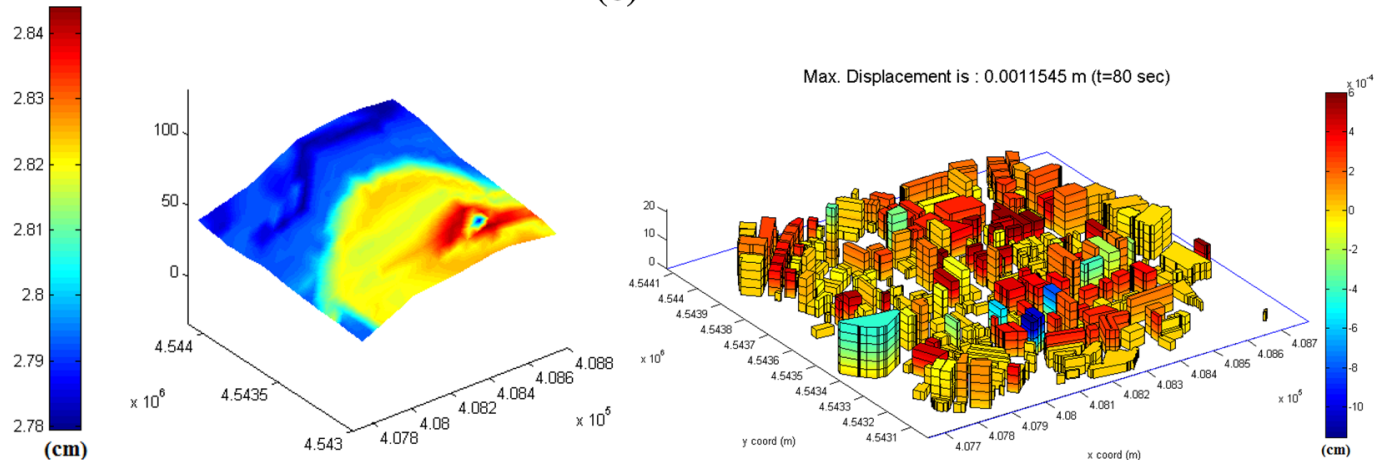

(d)

Fig. 21 Snapshots of the SGM distribution and the building set response in $\mathrm{N}-\mathrm{S}$ direction. a $t=50 \mathrm{~s}, \mathbf{b} t=60 \mathrm{~s}, \mathbf{c} t=70 \mathrm{~s}, \mathbf{d} t=80 \mathrm{~s}$ 


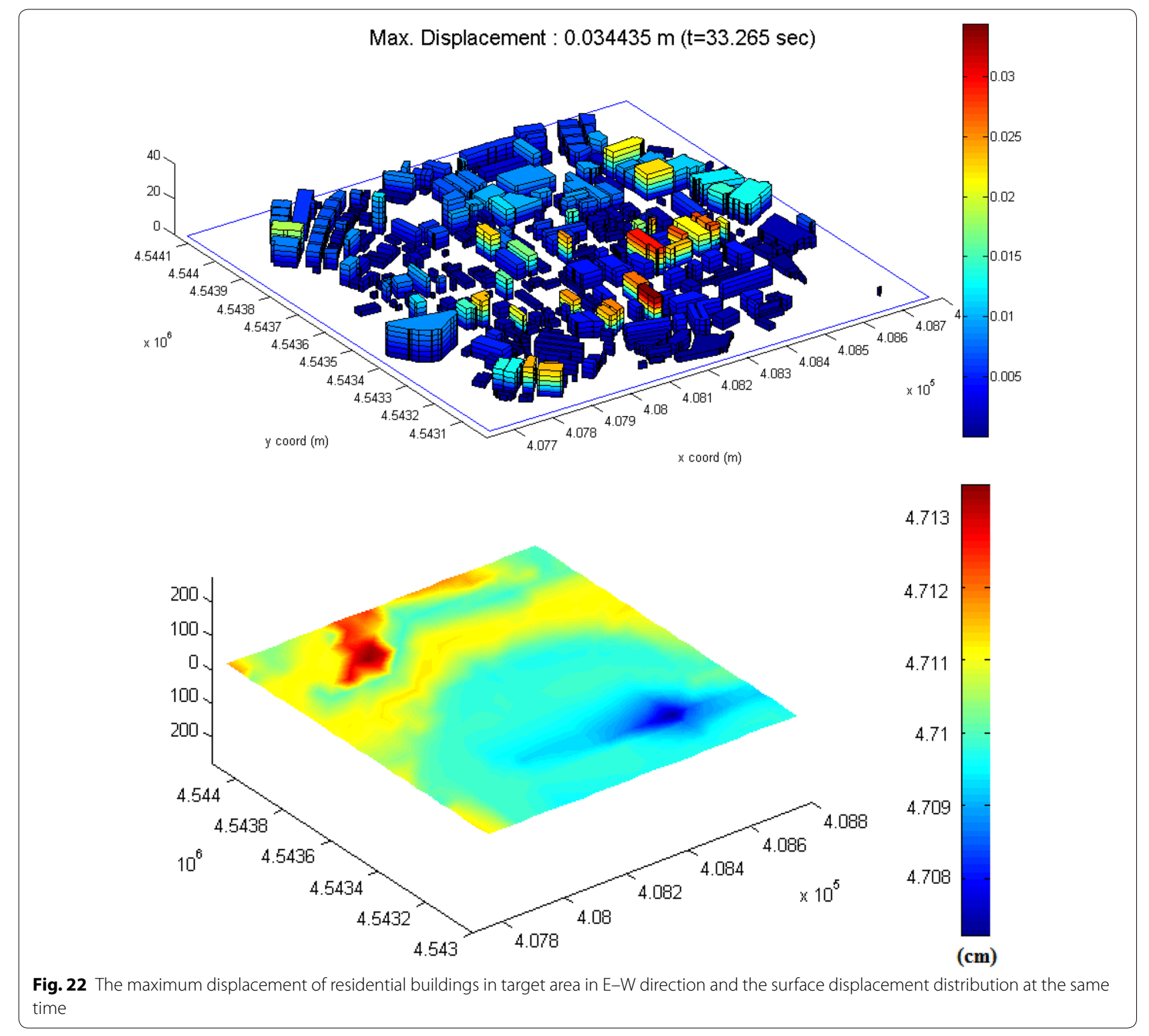

one-dimensional site response analysis is already implemented to account for the local soil amplifications. As input to these site response analyses, either a Ricker pulse or an observed velocity time history is employed. The observed time history is measured on a rock site during a previous earthquake that occurred in Istanbul. However, in order to model the effects of fault rupture process of past earthquakes as well as scenario events, a simulation tool to model the wave propagation from the rupture plane to each site is required. Since one-dimensional site response is already included, the basic goal in this section is to select and apply a robust approach for IES on MAT$\mathrm{LAB}$ to model the generation and propagation of the waves from the source to each site of interest. This way, the model will be complete and physical in terms of all of the source-to-structure components. 


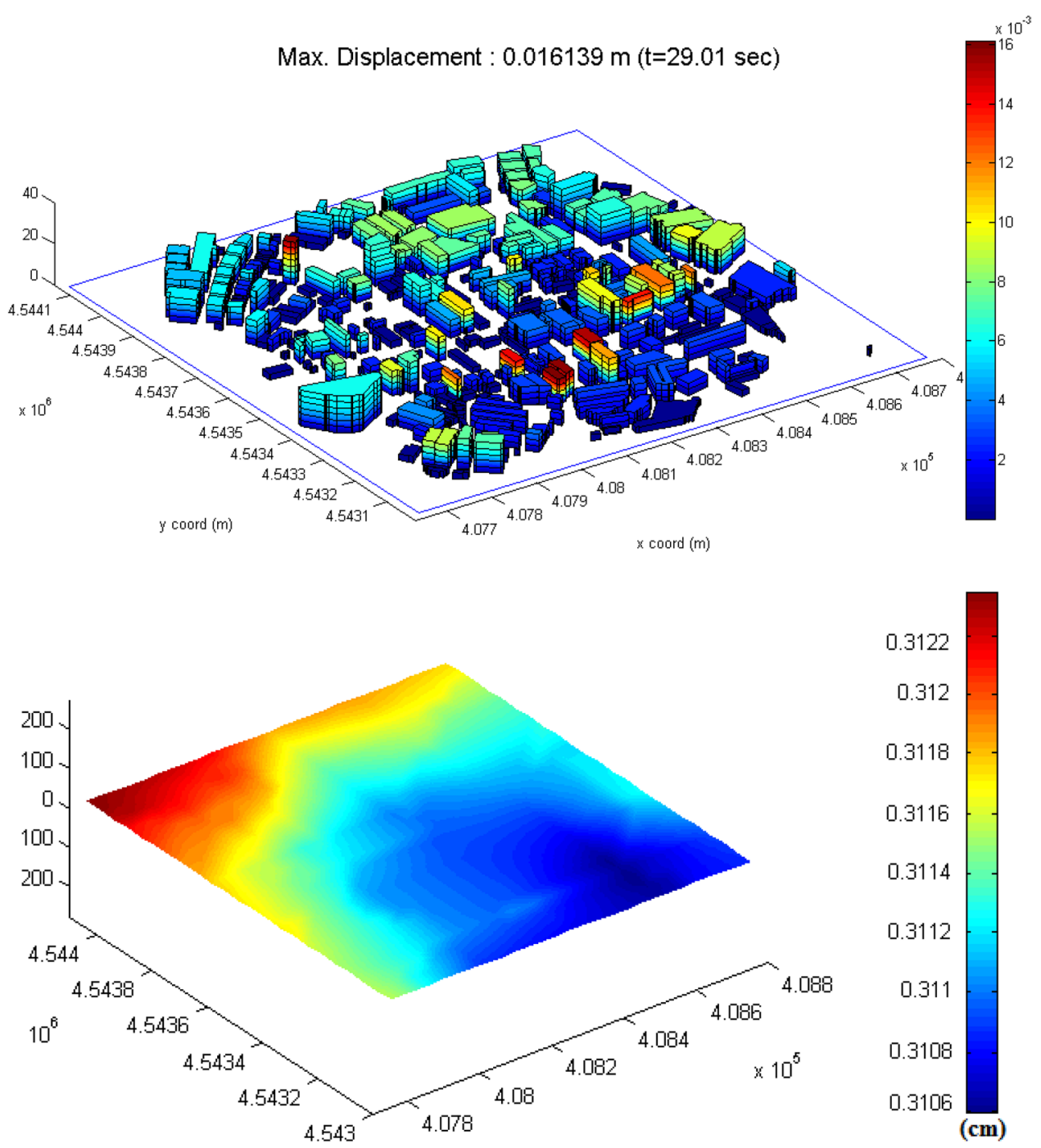

Fig. 23 The maximum displacement of residential buildings in target area in $\mathrm{N}-\mathrm{S}$ direction and the surface displacement distribution at the same time

A hybrid model composed of both deterministic (Spudich and $\mathrm{Xu} 2003$ ) and stochastic (e.g., Motazedian and Atkinson 2005; Askan et al. 2013) approaches for waveform modeling will be employed. Validation of our ground motion simulations will be performed against previous events in the region. Since there is no large event in Istanbul that occurred in the instrumental era, the records are obtained only from the small events. Finally, after validations, we will perform finite-fault simulations for potential large earthquakes in Istanbul in the final form of IES on MATLAB. Results will be presented as ground motions on free surface as well as building responses. Spatial distributions of ground and structural responses for 


\section{Max. Displacement : $0.034534 \mathrm{~m}(\mathrm{t}=33.265 \mathrm{sec})$}

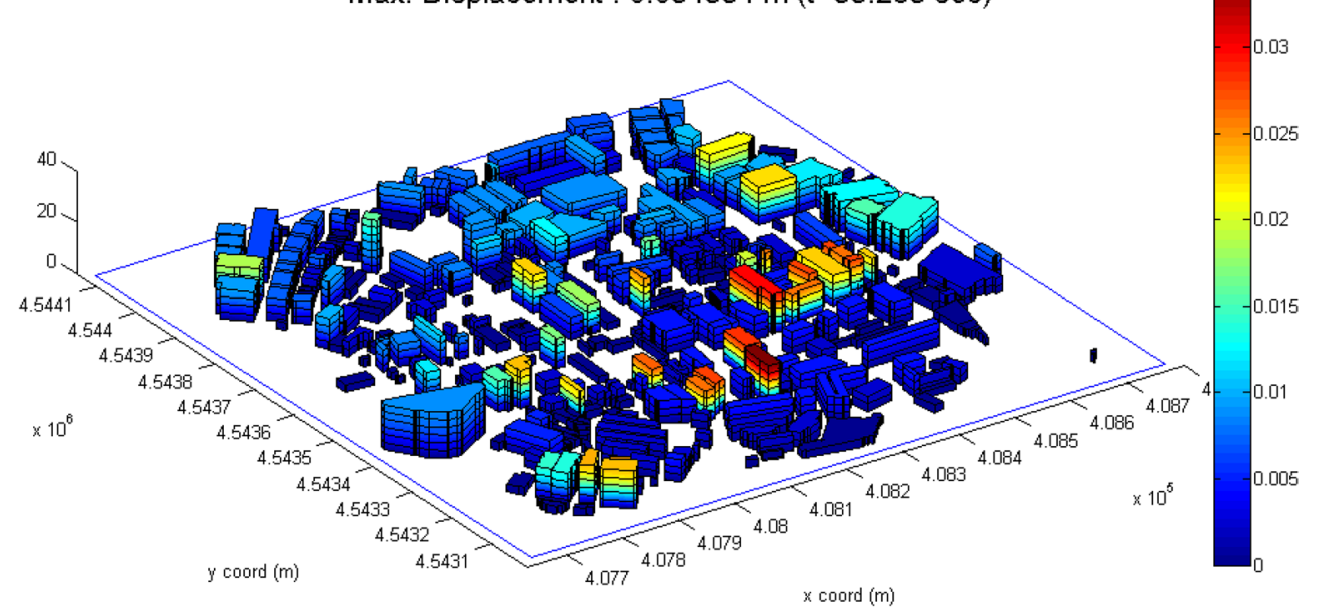

Fig. 24 The maximum combined displacement of residential buildings in target area due to both seismic records

different earthquake scenarios could be employed for a range of purposes including disaster mitigation and emergency management.

\section{Authors' contributions}

AS participated in development of CitySeis and SoVeLAB tools and carried out city simulation, RS participated in development of SoVeLAB tool, AA participated in the design of the study, evaluated the obtained results, and helped to draft the manuscript, and $\mathrm{MH}$ participated in design of study and coordination and helped to draft the manuscript. All authors read and approved the final manuscript.

\section{Author details}

${ }^{1}$ Department of Civil Engineering, Yıldız Technical University, Istanbul, Turkey.

${ }^{2}$ Department of Civil Engineering, Middle East Technical University, Ankara,

Turkey. ${ }^{3}$ Earthquake Research Institute, University of Tokyo, Tokyo, Japan.

\section{Acknowledgements}

This research is supported by the Scientific and Technological Research Council of Turkey-TUBITAK — under Research Grant No 315M056. The soil model has been developed by using the database in Istanbul Metropolitan Municipality (IMM) servers under the protocol signed for the SATREPS-MarDim project (Earthquake and Tsunami Disaster Mitigation in the Marmara Region and Disaster Education in Turkey).

Received: 9 April 2015 Accepted: 22 June 2016

Published online: 12 July 2016

\section{References}

Ansal A, Akinci G, Cultrera M, Erdik V, Pessina G, Tonuk G (2009) Loss estimation in Istanbul based on deterministic earthquake scenarios of the Marmara Sea Region (Turkey). Soil Dyn Earthq Eng 29(4):699-709

Askan A, Sisman FN, Ugurhan B (2013) Stochastic strong ground motion simulations in sparsely-monitored regions: a validation and sensitivity study on the 13 March 1992 Erzincan (Turkey) earthquake. Soil Dyn Earthq Eng 55:170-181

Atakan K, Ojeda A, Meghraoui M, Barka AA, Erdik M, Bodare A (2002) Seismic hazard in Istanbul following the 17 August 1999 Izmit and 12 November 1999 Duzce earthquakes. Bull Seism Soc Am 92:466-482
Bal IE, Crowley H, Pinho R (2008) Displacement-based earthquake loss assessment for an earthquake scenario in Istanbul. J Earthq Eng 12(S2):12-22

Erdik M, Aydinoglu N, Fahjan Y, Sesetyan K, Demircioglu M, Siyahi B, Durukal E, Ozbey C, Biro Y, Akman H, Yuzugullu O (2003) Earthquake risk assessment for Istanbul Metropolitan area. Earthq Eng Eng Vib 2(1):1-25

Erdik M, Sesetyan K, Demircioglu MB, Hancilar U, Zulfikar C, Cakti E, Kamer Y, Yenidogan C, Tuzun C, Cagnan Z, Harmandar E (2010) Rapid earthquake hazard and loss assessment for Euro-Mediterranean Region. Acta Geophys 58(5):855-892

Erdik M, Sesetyan K, Demircioglu MB, Hancilar U, Zulfikar C (2011) Rapid earthquake loss assessment after damaging earthquakes. Soil Dyn Earthq Eng 31(2):247-266

Hancilar U, Tuzun C, Yenidogan C, Erdik M (2010) ELER software-a new tool for urban earthquake loss assessment. Nat Hazards Earth Syst Sci 10:2677-2696

Hori M (2007) Introduction to computational earthquake engineering. Imperial College Press, London (2nd edition in 2011)

Hori M, Ichimura T (2008) Current state of integrated earthquake simulation for earthquake hazard and disaster. J Seismol 12(2):307-321

Karaman H, Şahin M, Elnashai AS (2008a) Earthquake loss assessment features of Maeviz-Istanbul (HAZTURK). J Eartha Eng 12(2):175-186

Karaman H, Şahin M, Elnashai AS, Pineda O (2008b) Loss assessment study for the Zeytinburnu district of Istanbul using Maeviz-Istanbul (HAZTURK). J Earthq Eng 12(2):187-198

Matlab ${ }^{\circledR}$ Parallel Computing Toolbox ${ }^{\mathrm{TM}}$ Users Guide (2015), The MathWorks, Inc Matlab ${ }^{\circledR}$ The Language of Technical Computing (2015), The MathWorks, Inc

Motazedian D, Atkinson GM (2005) Stochastic finite-fault modeling based on a dynamic corner frequency. Bull Seism Soc Am 95:995-1010

Pacific Consultants International/OYO Corporation (2002) The study on a disaster prevention/mitigation basic plan in Istanbul including seismic microzonation in the Republic of Turkey, Final report submitted to Japan International Cooperation Agency (JICA) and İstanbul Metropolitan Municipality

Sahin A (2011) Mathematical models and solution algorithms for computational design of RC piles under structural effects. Appl Math Model 35(7):3611-3638

Sahin A (2012) A new algorithm for geometrical design of asymmetric tall buildings against seismic torsional behavior. Struct Des Tall Spec Build 21(9):642-668

Sahin A (2014) Simulation of earthquake hazards and disasters - use of integrated earthquake simulation (IES) for urban areas, TUBITAK 2219 International Post Doctoral Research Fellowship Programme-Final Report

Sahin A (2015a) Dynamic simulation models for seismic behavior of soil systems—Part l: block diagrams. J Geomech Eng 9(2):145-167 
Sahin A (2015b) Dynamic simulation models for seismic behavior of soil systems-Part II: solution algorithm and numerical applications. J Geomech Eng 9(2):169-193

Sesetyan K, Zulfikar C, Demircioglu M, Hancilar U (2011) Istanbul earthquake rapid response system: methods and practices. Soil Dyn Earthq Eng 31(2):170-180
Spudich P, Xu L (2003) Documentation of software package COMPSYN: programs for earthquake ground motion calculations using complete 1-D green's functions. CD accompanying IASPEI handbook of earthquake and engineering seismology. Academic Press, Cambridge, p 56

URL 1: http://ngawest2.berkeley.edu/ (23.02.2015)

\section{Submit your manuscript to a SpringerOpen ${ }^{\circ}$ journal and benefit from:}

- Convenient online submission

\section{- Rigorous peer review}

Immediate publication on acceptance

- Open access: articles freely available online

- High visibility within the field

- Retaining the copyright to your article 